\title{
Copper-mediated thiol potentiation and mutagenesis-guided modeling suggest a highly conserved copper-binding motif in human OR2M3
}

\author{
Franziska Haag ${ }^{1}$. Lucky Ahmed ${ }^{2} \cdot$ Krystle Reiss $^{2} \cdot$ Eric Block $^{3} \cdot$ Victor S. Batista $^{2}$ - Dietmar Krautwurst ${ }^{1}$ (D)
}

Received: 5 November 2018 / Revised: 7 August 2019 / Accepted: 12 August 2019 / Published online: 21 August 2019

(c) The Author(s) 2019

\begin{abstract}
Sulfur-containing compounds within a physiological relevant, natural odor space, such as the key food odorants, typically constitute the group of volatiles with the lowest odor thresholds. The observation that certain metals, such as copper, potentiate the smell of sulfur-containing, metal-coordinating odorants led to the hypothesis that their cognate receptors are metalloproteins. However, experimental evidence is sparse — so far, only one human odorant receptor, OR2T11, and a few mouse receptors, have been reported to be activated by sulfur-containing odorants in a copper-dependent way, while the activation of other receptors by sulfur-containing odorants did not depend on the presence of metals. Here we identified an evolutionary conserved putative copper interaction motif CC/CSSH, comprising two copper-binding sites in TMH5 and TMH6, together with the binding pocket for 3-mercapto-2-methylpentan-1-ol in the narrowly tuned human receptor OR2M3. To characterize the copper-binding motif, we combined homology modeling, docking studies, site-directed mutagenesis, and functional expression of recombinant ORs in a cell-based, real-time luminescence assay. Ligand activation of OR2M3 was potentiated in the presence of copper. This effect of copper was mimicked by ionic and colloidal silver. In two broadly tuned receptors, OR1A1 and OR2W1, which did not reveal a putative copper interaction motif, activation by their most potent, sulfur-containing key food odorants did not depend on the presence of copper. Our results suggest a highly conserved putative copper-binding motif to be necessary for a copper-modulated and thiol-specific function of members from three subfamilies of family 2 ORs.
\end{abstract}

Keywords GPCR $\cdot$ Structure-function study $\cdot$ Molecular modeling $\cdot$ Copper-binding motif $\cdot$ Silver ions

$\begin{array}{ll}\text { Abbreviations } \\ \text { AA } & \text { Amino acid } \\ \text { ECL } & \text { Extracellular loop } \\ \text { GPCR } & \text { G-protein coupled receptor } \\ \text { KFO } & \text { Key food odorant }\end{array}$

Electronic supplementary material The online version of this article (https://doi.org/10.1007/s00018-019-03279-y) contains supplementary material, which is available to authorized users.

Dietmar Krautwurst

d.krautwurst.leibniz-lsb@tum.de

1 Leibniz-Institute for Food Systems Biology, Technical University of Munich, Lise-Meitner-Str. 34, 85354 Freising, Germany

2 Department of Chemistry, Yale University, New Haven, CT 06520, USA

3 Department of Chemistry, University at Albany, State University of New York, Albany, NY 12222, USA
MAF Minor allele frequency

MC Melanocortin receptor

OR Odorant receptor

OSN Olfactory sensory neuron

SNP Single-nucleotide polymorphism

TMH Transmembrane helix

\section{Introduction}

The perception of odors of all kinds is initiated by binding to $\mathrm{G}$ protein-coupled receptors (GPCRs), encoded by about 400 odorant receptor (OR) genes [1-3], of which at least 270 appear to be expressed in the cilia of olfactory sensory neurons (OSNs) within the main olfactory epithelium (OE) of the nasal cavity [4]. Odor coding is then achieved in a combinatorial manner whereby more ORs are broadly tuned than narrowly tuned and whereby one odorant may activate multiple ORs [5-14]. 
Thiols play an outstanding role in human olfaction, for instance as body odor [15-19], environmental odors [20], and especially as key food odorants (KFOs), which appear in foods at concentrations above their odor threshold, and critically determine the aroma of foods [21]. Thiol odorants often show very low odor thresholds [6, 21-25]. The olfactory sensitivity for thiols is shown not only for humans but also for spider monkeys (Ateles geoffroyi), squirrel monkeys (Saimiri sciureus), and pigtail macaque (Macaca nemestrina) [26]. Interestingly, these low odor thresholds have been associated with the presence of ions from transition metals such as copper, iron, zinc, or nickel [27-32]. Because of the remarkable olfactory potency of thiols, several theories have been put forward to explain this behavior.

In 1978, Crabtree [27] postulated that $\mathrm{Cu}(\mathrm{I})$ ions, because of their high affinity for thiols, coordinate them within the active center of odorant receptors, thereby constituting a sensitive thiol detector [27]. In the same year, Day [33] suggested that transition metals may be involved in the olfaction of certain functional groups, such as pyridines [33].

In 1996, Turin [34] published the so-called vibrational theory of olfaction [34], proposing that electron transfer, which is ubiquitous in biology, e.g., for photosynthesis, respiration, and nitrogen fixation, takes place in the OR protein by reducing the disulfide bond via a zinc ion [34].

In 2003, Wang et al. [28] postulated the "HxxC[DE]"amino acid-motif (with $\mathrm{x}$ as a hydrophobic residue) in the second extracellular loop (ECL 2) of ORs to be crucially involved in the coordination of $\mathrm{Cu}^{2+}$ - or $\mathrm{Zn}^{2+}$-ions and odorants within their receptors. They could observe a conformational change of this motif from pleated sheet to an $\alpha$-helix in the presence of $\mathrm{Zn}^{2+}$, suggesting that ECL 2 becomes engaged in odorant binding [28]. The consensus sequence "HxxC[DE]" can be found in 74\% of all human ORs, which led them to propose ORs as metalloproteins [28]. The role of metals in mammalian olfaction is the subject of recent reviews $[35,36]$.

In addition to ORs, other GPCRs have also been suggested to coordinate metal ions. For example, the binding of ligands in the opioid receptor is enhanced by manganese [37]. By introducing $\mathrm{Cu}^{2+}, \mathrm{Zn}^{2+}$, or $\mathrm{Ni}^{2+}$ ions into cyclam rings of AMD3100, the response of the CXCR4 chemokine receptor could be increased up to 50-fold [38]. Mutational analysis revealed that the enhancing effect could be eliminated by changing the single amino acid Asp262 in TMH 6 [38]. Furthermore, the two melanocortin receptors MC1 and MC4 have been shown to be enhanced by $\mathrm{Zn}^{2+}$ [39]. $\mathrm{MC} 1$ is expressed in melanocytes and controls skin tanning. MC4 expresses in certain regions of the hypothalamus in the brain, and within the intestinal tissue. It is involved in the regulation of autonomic responses as well as the regulation of energy homeostasis. Possible interaction sites were indicated as Cys271 (ECL 3) and Asp119 (extracellular end of TMH 3) [39]. Transition metals such as copper, zinc, and iron play an important role for the homeostasis of brain neurons [40, 41]. Aron et al. [42] showed that metals like copper can serve as dynamic signals that bind and regulate protein function at external allosteric sites in addition to their function as static metabolic cofactors [42].

Yokoi et al. [43] investigated dietary nickel deprivation on olfaction in rats and observed a decreased sniffing rate [43]. Since olfactory CNG channels are suppressed by nickel $[44,45]$, they suggested that nickel ions play a physiological role in olfactory function.

Viswaprakash et al. [46] reported zinc to enhance the odorant-induced responses in olfactory receptor neurons [46]. They observed an enhancement of signaling in these neurons, however, only using nanoparticles, but not using $\mathrm{Zn}^{2+}$ ions [46]. Furthermore, the use of copper, gold, or silver nanoparticles did not show a similar effect as compared to zinc nanoparticles [46]. Also Vodyanoy [47] investigated zinc nanoparticles, and came up with a model that predicted that one metal nanoparticle binds two receptor molecules to create a receptor dimer, which is consistent with the evidence that many GPCRs form dimers or larger oligomers [47]. In a later study, they showed that nanomolar suspensions of zinc nanoparticles enhance responses by a factor of 5 [48].

In 2012, Duan et al. [29] suggested $\mathrm{Cu}^{2+}$ ions to be an essential co-factor for the interaction of mouse OR Olfr 1509 (MOR244-3) with its agonist (methylthio)methanethiol [29]. Since increasing the copper concentration in the cell-based assay led to a significant increase of the sensitivity of the receptor, whereas chelating agents decreased the receptor's sensitivity, they postulated that thiols and copper ions form a complex, which renders the receptor very sensitive for thiols [29]. Based on this study, and by combining receptor modeling/ligand docking, site-directed mutagenesis, and functional expression of recombinant mutant OR, Sekharan et al. [30] identified three amino acid positions within TMH 3 and TMH 5, His105 $5^{3.33}$, Cys109 ${ }^{3.37}$, and Asn202 $2^{5.42}$, which supposedly form a Cu-binding site within receptor Olfr1509 [30].

Most recently, Zhang et al. [32] de-orphanized another mouse OR for (methylthio)methanethiol which also shows a copper effect. For Olfr1019 (MOR180-1), the amino acid positions within TMH 5 and TMH 6, Cys203 $3^{5.42}$, Met256 6.48 , and $\operatorname{Arg} 261^{6.53}$, supposedly form a Cu-binding site within the receptor.

Furthermore, Li et al. [31] demonstrated that activation of human OR2T11 by small thiols mainly containing up to five carbon atoms depended on the presence of transition metal ions [31]. They identified two Cu-binding sites within OR2T11, which involve Met115 $5^{3.46}$ of TMH 3, and residues Cys $238^{6.33}$ and His $241^{6.35}$ from TMH 6, or Met56 2.39 of TMH 2, and Met $133^{4.37}, \operatorname{Arg} 135^{4.39}$, and Cys $138^{4.42}$ of TMH 4 [31]. 
However, the mechanisms underlying the very sensitive detection of thiols by humans in general are still unsolved. So far, the $\mathrm{Cu}$ dependence of ORs' responsiveness to thiols has been demonstrated for one human OR [31] and a few mouse ORs [29, 32]. Most of the thiol-responsive human ORs identified, so far are members of family 2 of ORs [5, 6, 11-13, 31, 49]. Recently, we identified one narrowly tuned thiol-responding human receptor, OR2M3, as well as two broadly tuned receptors with overlapping thiol agonist spectra $[5,6]$. One causative mechanism for differences in tuning breadth may be the size of the respective ligand-binding pockets. Baud et al. suggested this for mouse receptors Olfr73 and Olfr74 [50]. Here, the ligand cavity size showed an accessible volume of $200 \AA^{3}$ for broadly tuned Olfr 73 , and $250 \AA^{3}$ for narrowly tuned Olfr74 [50].

We, therefore, hypothesized that rather narrowly tuned, thiol-specific ORs may exhibit a $\mathrm{Cu}$ potentiating effect on their responsiveness to thiols, and that these ORs have rather size-restricted binding pockets with limited degrees of freedom for alternative docking of thiols into their receptors. In contrast, broadly tuned ORs with larger binding pockets will lack a $\mathrm{Cu}$ potentiating effect on thiol activation, but, among many chemically diverse odorant agonists, may nevertheless also detect certain thiol structures.

Here, we investigated narrowly tuned OR2M 3 with its agonist 3-mercapto-2-methylpentan-1-ol [6], a common and potent KFO from heated onions, which for thousands of years have been used worldwide as a food and in complementary medicine [51]. We compared OR2M3 with two most recently characterized broadly tuned receptors, OR2W1 and OR1A1, with three of their known agonists, 2-phenylethanethiol, 3-mercaptohexyl acetate, and allyl phenyl acetate [5], in a cell-based, online cAMP-luminescence GloSensor $^{\mathrm{TM}}$ assay [52].

We used site-directed mutagenesis and functional expression of recombinant mutant ORs to investigate cognate human OR/KFO pairs in the presence and absence of $\mathrm{Cu}^{2+}$-ions. We rationalized the docking of specific thiols into the binding pockets of their respective ORs with QM/MM models involving chelation of copper by these thiols and compared the size of thiol-binding pockets between narrowly tuned thiol-specific OR2M3 and broadly tuned OR2W1. We found the effect of copper to be mimicked by ionic and colloidal silver.

\section{Materials and methods}

\section{Chemicals}

The following chemicals were used: Dulbecco's MEM medium (\#F0435), FBS superior (\#S0615), L-glutamin (\#K0282), penicillin $(10000 \mathrm{U} / \mathrm{mL}) /$ streptomycin $(10$
000U/mL) (\#A2212), trypsin/EDTA solution (\#L2143) (Biochrom, Berlin, Germany), MEM non-essential amino acid solution (100x) (\#M7145, Sigma-Aldrich, Steinheim, Germany), Gibco ${ }^{\circledR}$ HAT supplement (\#21060-017, Thermo Fisher, Dreieich, Germany), calcium chloride dihydrate (\#22322.295), D-glucose (\#101174Y), dimethyl sulfoxide (DMSO) (\#83673.230), HEPES (\#441476L), potassium chloride (\#26764.230), and sodium hydroxide (\#28244.295) (VWR Chemicals BDH Prolabo, Leuven, Belgium), sodium chloride (\#1064041000, Merck, Darmstadt, Germany), D-luciferin (beetle) monosodium salt (\#E464X, Promega, Madison, USA), copper(II) chloride (\#751944), nickel(II) chloride hexahydrate (\#31462), zinc sulfate heptahydrate (\#Z0251), cobalt(II) chloride hexahydrate (\#C8661), iron(III) chloride (\#12321), colloidal silver (\#85131), silver acetate (\#8.01504.0005), silver nitrate (\#1.01512.0025), tertaethylenepentamine pentahydrochloride (TEPA) (\#375683, Sigma-Aldrich, Steinheim, Germany).

The odorants used were 3-mercapto-2-methylpentan1-ol (\#242803), 3-mercapothexyl acetate (\#137912, Chemos GmbH, Regenstauf, Germany), 2-phenylethanethiol (\#P1715, TCI Deutschland GmbH, Eschborn, Germany), allyl phenyl acetate (\#W203904), and (R)-(-)-carvone (\#124931, Sigma-Aldrich, Steinheim, Germany). All odorants were tested to be GC-O pure.

\section{Molecular cloning of human OR2M3, OR2W1, and OR1A1}

The protein-coding regions of human OR2M3 (NCBI reference sequence: NM_001004689.1), OR2W1 (NCBI reference sequence: NM_030903.3), and OR1A1 (NCBI reference sequence: NM_014565.2) were amplified from human genomic DNA by polymerase chain reaction (PCR) using gene-specific primers (Table S1), ligated with T4-DNA ligase (\#M1804, Promega, Madison, USA) either MfeI/NotI for OR2M3 and OR1A1 (\#R0589S/\#R0189S, New England BioLabs, Ipswich, USA) or EcoRI/NotI for OR2W1 (\#R6017/\#R6435, Promega, Madison, USA) into the expression plasmid pI2-dk(39aa-rhotag) (aa, amino acid) [53, 54], and verified by Sanger sequencing (Eurofins Genomics, Ebersberg, Germany).

\section{PCR-based site-directed mutagenesis}

All receptor variants used were generated by PCR-based site-directed mutagenesis in two steps. Gene-specific primers (mutation primers) were used according to Table S2 and Table S3. The mutation primers, which carried the changed nucleotides, were designed overlapping.

Step one PCR was carried out in two PCR amplifications, one with the forward gene-specific primer and the reverse mutation-primer, the other with the forward mutation-primer and the reverse gene-specific or vector-internal primer. 
Both PCR amplicons were then purified and used as template for step two. Here, the two overlapping amplicons were annealed using the following program: denaturation $\left(98^{\circ} \mathrm{C}\right.$, $3 \mathrm{~min})$, ten cycles containing denaturation $\left(98^{\circ} \mathrm{C}, 30 \mathrm{~s}\right)$, annealing (start $58^{\circ} \mathrm{C}, 30 \mathrm{~s}$ ), and extension $\left(72{ }^{\circ} \mathrm{C}, 2 \mathrm{~min}\right)$. After this, full-length gene-specific forward and reverse primers were added. The amplicons were then sub-cloned as described above.

\section{Sequencing}

All sub-cloned wild-type (wt) and mutated OR-coding amplicons were verified by Sanger sequencing (Eurofins Genomics, Ebersberg, Germany) using vector-internal primers (Table S4).

\section{Cell culture and transient DNA transfection}

We used NxG 108CC15 cells [55], a neuroblastoma x glioma hybrid, and HEK-293 cells [56], a human embryonic kidney cell-line, as a test cell system for the functional expression of recombinant OR [52].

$\mathrm{NxG} 108 \mathrm{CC} 15$ cells were cultivated at $37{ }^{\circ} \mathrm{C}, 7 \% \mathrm{CO}_{2}$, and $100 \%$ humidity in $4.5 \mathrm{~g} / \mathrm{L}$ D-glucose containing DMEM with $10 \%$ fetal bovine serum, $4 \mathrm{mmol} / \mathrm{L}$ L-glutamine, $100 \mathrm{U} /$ $\mathrm{mL}$ penicillin, and $100 \mathrm{U} / \mathrm{mL}$ streptomycin, $100 \mu \mathrm{mol} / \mathrm{L}$ hypoxanthine, $0.4 \mu \mathrm{mol} / \mathrm{L}$ aminopterin, $16 \mu \mathrm{mol} / \mathrm{L}$ thymidine (HAT media supplement), and $1 \%$ of $100 \times$ MEM nonessential amino acid solution (NEAA). HEK-293 cells were cultivated at $37{ }^{\circ} \mathrm{C}, 5 \% \mathrm{CO}_{2}$, and $100 \%$ humidity in $4.5 \mathrm{~g} / \mathrm{L}$ D-glucose containing DMEM with $10 \%$ fetal bovine serum, $2 \mathrm{mM}$ L-glutamine, $100 \mathrm{U} / \mathrm{mL}$ penicillin, and $100 \mathrm{U} / \mathrm{mL}$ streptomycin.

For experiments, cells were plated in a 96-well format (white 96-well plate, Nunc, Roskilde, Denmark) with a density of 7500 cells per well for NxG $108 \mathrm{CC} 15$ cells and 12,000 cells per well for HEK-293 cells. On the next day, the transfection was performed by using the lipofection method with each $100 \mathrm{ng} /$ well of the corresponding plasmid DNA as well as with $50 \mathrm{ng} /$ well of the transport protein RTP1S [57], G protein subunit Goolf [54, 58], olfactory $G$ protein subunit G $\gamma 13$ [59], and the pGloSensor ${ }^{\mathrm{TM}}-22 \mathrm{~F}$ [60] (Promega, Madison, USA) using Lipofectamine ${ }^{\circledR} 2000$ (\#11668027, Life Technologies, USA). The pGloSensor ${ }^{\mathrm{TM}}-22 \mathrm{~F}$ is a genetically engineered luciferase with a cAMP-binding pocket, which allows measuring a direct cAMP-dependent luminescence signal. As a control the transfection was performed with the vector plasmid pI2-dk(39aa rho-tag) (aa, amino acids) [53, 54] which is lacking the coding information of an OR together with Goolf, RTP1S, G $\gamma 13$, and cAMP-luciferase pGloSensor ${ }^{\mathrm{TM}}-22 \mathrm{~F}$ (mock). The amount of transfected plasmid DNA was equal in OR-transfected and mock-transfected cells.

\section{Luminescence assay}

Luminescence assays were performed $42 \mathrm{~h}$ post-transfection as reported previously [52]. For experiments without copper, the cells were loaded with a physiological salt buffer ( $\mathrm{pH} 7.5$ ) containing $140 \mathrm{mmol} / \mathrm{L} \mathrm{NaCl}, 10 \mathrm{mmol} / \mathrm{L}$ HEPES, $5 \mathrm{mmol} / \mathrm{L} \mathrm{KCl}, 1 \mathrm{mmol} / \mathrm{L} \mathrm{CaCl}_{2}, 10 \mathrm{mmol} / \mathrm{L}$ glucose, and $2 \%$ of beetle luciferin sodium salt (Promega, Madison, USA). For the luminescence measurements, the Glomax ${ }^{\circledR}$ MULTI+detection system (Promega, Madison, USA) was used. After an incubation of the cells for $1 \mathrm{~h}$ in the dark, the basal luminescence signal of each well was recorded. Afterwards, the odorant, serially diluted in the physiological salt buffer, was applied to the cells. Odorant stock solutions were prepared in DMSO and diluted 1:1000 in the physiological salt buffer to obtain a final DMSO concentration of $0.1 \%$ DMSO on the cells. To keep all measurement conditions the same, the water-soluble substances were also dissolved in DMSO. For odorants which were only slightly soluble, we added Pluronic PE-10500 (BASF, Ludwigshafen, Germany) to the buffer. The final Pluronic PE-10500 concentration on the cells was $0.05 \%$.

Real-time luminescence signals for each well were measured 4 min after the odorant application.

For the measurements with copper, we added a final concentration of $10 \mu \mathrm{mol} / \mathrm{L}$ of a $10 \mathrm{mmol} / \mathrm{L} \mathrm{CuCl}_{2}$ solution to the normal measurement buffer as described above. The assay was performed as reported above.

\section{Data analysis of the CAMP-luminescence measurements}

The raw luminescence data obtained from the Glomax ${ }^{\circledR}$ MULTI + detection system were analyzed using Instinct Software (Promega, USA). Data points of basal level and data points after odorant application were each averaged. From each luminescence signal, the corresponding basal level was subtracted.

For concentration-response relations, the baseline-corrected data set was normalized to the maximum amplitude of the reference odorant-receptor pair. The data set for the mock control was subtracted and $\mathrm{EC}_{50}$ values and curves were derived from fitting the function

$f(x)=\left(\frac{(\min -\max )}{\left(1+\left(\frac{x}{E C_{50}}\right)^{\text {Hillslope }}\right)}\right)+\max$ 
[61] to the data by nonlinear regression (SigmaPlot 10.0, Systat Software). All data are presented as mean \pm SD.

\section{Homology modeling and docking}

Details on the homology model approach for OR2M3 and OR2W1: we used the default setting in MPI Bioinformatics Toolkit server (https://toolkit.tuebingen.mpg.de/\#/tools/ hhpred), which uses the Modeller program [62] to model the homology model. We built the homology model of OR2M3 using the X-ray structure of the M1 muscarinic receptor as a template (5CXV.pdb) [63]. The comparative protein modeling with available $\mathrm{X}$-ray structures indicates a high sequence identity between the OR2M3 and the M1 receptor transmembrane helix regions. Figure $\mathrm{S} 1$ shows the sequence alignment of the human M1 muscarinic receptor (green) and human olfactory receptor OR2M3 (red) as obtained using the Multiple Sequence Viewer implemented in Maestro (Schrödinger Release 2016-3: Maestro, Schrödinger, LLC, New York, NY, 2016.). The TMH domains were obtained using the transmembrane hidden Markov Model (TMHMM) analysis, as applied to model OR5AN1 [64] and OR2T11 [31], using the TMHMM server (http://www.cbs.dtu.dk/ services/TMHMM/) based on Bayesian analysis of a pool of transmembrane proteins with resolved structures. As shown in Figure S2, OR2M3 residues with a posterior TMH probability greater than 0.2 were assigned to the transmembrane domain. Similarly, the homology model of OR2W1 was built using the same template (5CXV.pdb), and the TMH regions were obtained by TMHMM analysis. Figure $\mathrm{S} 3$ shows the superposition of structures corresponding to the sequence alignment of TMH regions of OR2M3 (red) and OR2W1 (blue) with the human M1 muscarinic receptor (green). As shown in Figure S4, OR2W1 residues with a posterior TMH probability greater than 0.2 were assigned to the transmembrane domain.

Docking setup All docking calculations were carried out in the Schrödinger Suite (Small-Molecule Drug Discovery Suite 2016-3, Schrödinger, LLC, New York, NY, 2016.). The initial coordinates of the homology model of the OR2W1 structure were obtained from the homology model as described in the homology model section. Glide SP (standard precision) protocol implemented in Schrödinger Suite was applied for docking (Schrödinger Release 20163: Glide, Schrödinger, LLC, New York, NY, 2016.). The receptor was checked for steric clashes as well as for correct protonation states in the protein. The protonation states of all titratable residues $(\mathrm{pH}=7)$ are assigned using PROPKA calculations $[65,66]$ implemented in the Schrodinger's Maestro v.9.3 software package (Schrödinger Release 20163: Maestro, Schrödinger, LLC, New York, NY, 2016.) and also by visual inspection. Then the receptor was optimized by applying the OPLS_2005 force field [67]. The ligand was docked into the OR2W1 homology model using the GLIDE module [68-70] implemented in the Schrodinger's Maestro v.9.3 software package. GlideScore (standard precision) was used to rank the different ligands. GlideScore is an empirical scoring function that guesses the ligand-binding free energy. It includes force field (electrostatic and van der Waals) contributions and terms rewarding or penalizing interactions known to influence ligand binding. As it simulates a binding free energy, more negative values represent tighter binders.

\section{Molecular dynamic simulation}

Molecular dynamic simulations were carried out using the CHARMM36 force field implemented in the NAMD2 software [71]. The best docked pose of 3-mercaptohexyl acetate was used as the initial structure. The docking method is described in the docking section. The initial model system was inserted into a water box. After equilibration, production run MD simulations were carried out for 2 ns within the NPT ensemble at $298 \mathrm{~K}$ and $1.0 \mathrm{~atm}$ using the Langevin piston for $62 \mathrm{~ns}$ simulation time for the system (Fig. S5). Electrostatic interactions were treated with the Particle Mesh Ewald (PME) method and van der Waals interactions were calculated using a switching distance of $10 \AA$ and a cutoff of $12 \AA$. The time step integration was set to $1 \mathrm{fs}$.

\section{QM/MM calculations}

QM/MM calculations were performed on homology models using ONIOM method [72] as part of the Gaussian 09 software package [73]. The QM layer included the ligand, copper (if present), the copper/ligand-binding residues, and any waters in the binding pocket. For OR2M3, the QM residues were C202, C203, and T105 in site 1 and M118, C241, and H244 in site 2. DFT/M06-L [74, 75], and multiple basis sets were used to describe the QM layer. The 6-31G(d) basis set [76] was applied to carbon, hydrogen, nitrogen, sulfur, and oxygen atoms, and the Stuttgart 8s 7p6d2f and 6s5p3d2f ECP10MWB contracted pseudopotential basis set [77] was applied to the copper atom. The MM layer consisted of the remaining protein and was modeled with the AMBER96 force field [78].

\section{Phylogenetic analysis}

For sequence comparison, we used CLC Main Workbench 6.5. We used the same software to perform the ClustalW alignment of the transmembrane regions (TMH) 1-7 and the extracellular loop 2 of all human ORs, family 2 ORs and OR2M3, and 46 homolog receptors as well as 60 orthologs from mouse, rat, chimp, and dog of the three family 2 OR subfamilies $\mathrm{M}, \mathrm{T}$, and $\mathrm{V}$ (Table S5). We created sequence logos using WebLogo 2.8.2 [79, 80]. The localization of 
the TMHs of human OR2M3 and OR2W1 was taken from HORDE [81]. The evolutionary history of ORs was inferred using the Neighbor-Joining method [82]. Trees are drawn to scale, with branch lengths in the same units as those of the evolutionary distances used to infer each phylogenetic tree. The evolutionary distances were computed using the Poisson correction method [83] and are in the units of the number of amino acid substitutions per site. All evolutionary analyses were conducted in MEGA7 [84].

\section{Results}

\section{Copper ions enhanced a thiol agonist action on narrowly tuned OR2M3 but not on broadly tuned OR2W1}

Thiols are among the best KFO agonists of the two broadly tuned human odorant receptors OR1A1 and OR2W1 [5],
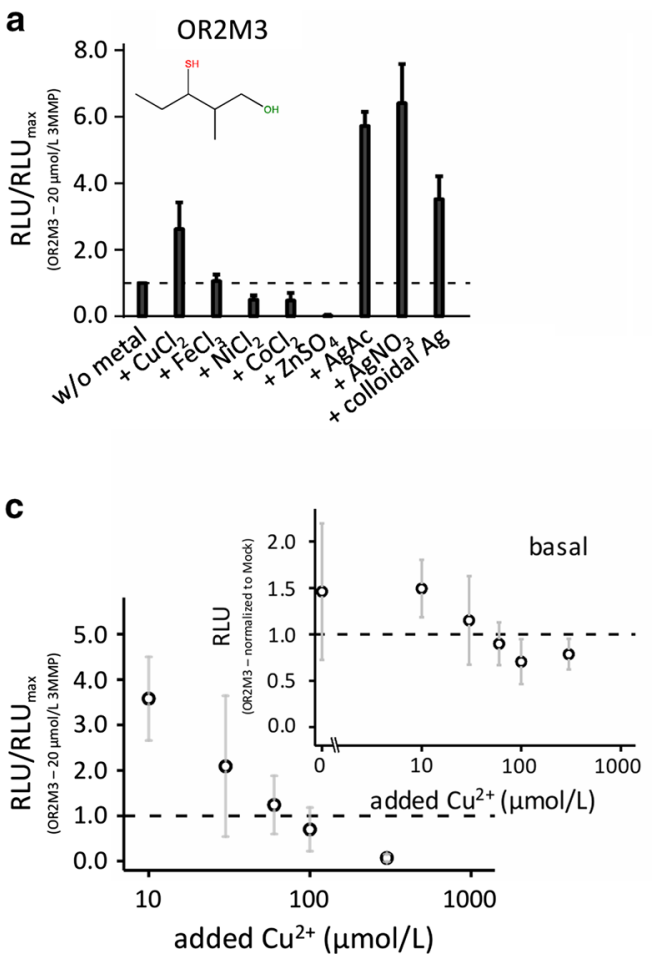

Fig. $1 \mathrm{Cu}^{2+}, \mathrm{Ag}^{+}$, and colloidal silver enhance the efficacy of 3-mercapto-2-methylpentan-1-ol on OR2M3. a Comparison of efficacies of $20 \mu \mathrm{mol} / \mathrm{L} 3$-mercapto-2-methylpentan-1-ol on OR2M3 in the absence or presence of different metal ions at $30 \mu \mathrm{mol} / \mathrm{L}$; $\mathbf{b}$ concentration-response relation of 3-mercapto-2-methylpentan-1-ol on OR2M3 in the absence or presence of $30 \mu \mathrm{mol} / \mathrm{L} \mathrm{Cu}{ }^{2+}$; $\mathbf{c}$ effect of $20 \mu \mathrm{mol} / \mathrm{L} 3$-mercapto-2-methylpentan-1-ol on OR2M3 in the presence of five different $\mathrm{Cu}^{2+}$ concentrations and effect of five different copper concentrations on the OR2M3 wt basal levels compared to the buffer without a copper supplementation (data were normalized to the mock basal level and shown as mean \pm SD $(n=5-10)$; d con- whereas OR2M3 has recently been demonstrated to specifically respond to only 3-mercapto-2-methylpentan-1-ol out of some 190 KFOs [6]. However, the influence of transition metal ions on these thiol/receptor interactions has not been tested so far. We, therefore, examined the effects of different metal ions at a final concentration of $30 \mu \mathrm{mol} / \mathrm{L}$ on the activation of OR2M3 by its agonist 3-mercapto-2-methylpentan-1-ol, an important KFO in heated onions [6], using the cAMP-dependent luminescence-based GloSensor ${ }^{\mathrm{TM}}$ assay (Fig. 1a, b, Fig. S6a, Table S6).

In the presence of $30 \mu \mathrm{mol} / \mathrm{L}$ supplemented $\mathrm{Cu}^{2+}$, we observed more than 2.5 -fold higher amplitudes in response to 3-mercapto-2-methylpentan-1-ol (Fig. 1a, b, Fig. S6a, Table S6). The presence of the copper chelator TEPA at $30 \mu \mathrm{mol} / \mathrm{L}$ not only prevented a $\mathrm{Cu}^{2+}$ potentiation, but largely reduced the ligand response of OR2M3 below normal conditions without $\mathrm{Cu}^{2+}$ supplementation (Fig. S6b), suggesting that residual $\mathrm{Cu}^{2+}$ was present in the commercial bath solution. Without $\mathrm{Cu}^{2+}$ supplementation, however, our

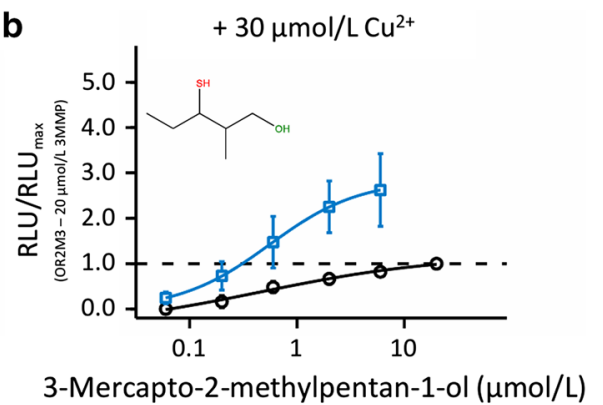

d
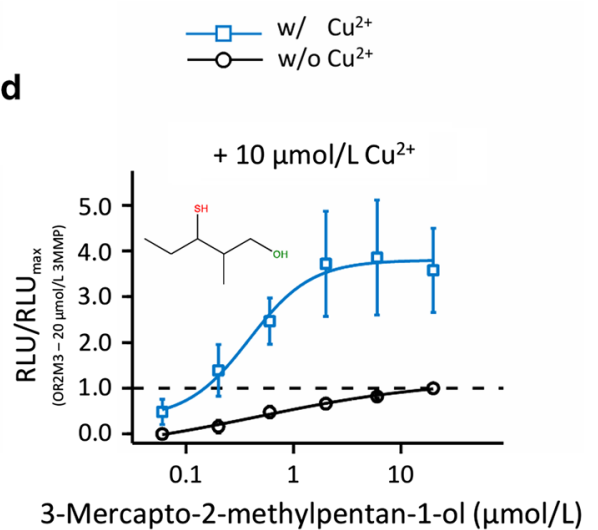

centration-response relation of 3-mercapto-2-methylpentan-1-ol on OR2M3 in the absence or presence of $10 \mu \mathrm{mol} / \mathrm{L} \mathrm{Cu}^{2+}$. Note that the same data set in the absence of supplemental $\mathrm{Cu}^{2+}$ (black) is given in sub-panels (b) and (d) for didactic reasons. Data were mock controlsubtracted, normalized to the OR2M3 wt signal in response to 3-mercapto-2-methylpentan-1-ol $(20 \mu \mathrm{mol} / \mathrm{L})$, measured in the absence of $\mathrm{Cu}^{2+}$, and shown as mean $\pm \mathrm{SD}(n=3-6) . R L U$ relative luminescence unit, 3MMP 3-mercapto-2-methylpentan-1-ol. The concentrationresponse relation Fig. 1b and Fig. S6a as well as Fig. 1d and Fig. S7a are the identical data set. Also Fig. 1a and Fig. S6 k as well as Fig. 1c and Fig. S7f are the identical data set 
method could not resolve any ligand-induced amplitudes of OR2T11 (Fig. S6c), suggesting that any residual $\mathrm{Cu}^{2+}$ in the commercial bath solution was insufficient for a potentiating effect on ligand-induced signaling of OR2T11 (see also [31]). $\mathrm{Fe}^{3+}$ was without effect (Fig. 1a, Fig. S6d, Table S6), but the presence of $\mathrm{Ni}^{2+}$ or $\mathrm{Co}^{2+}$ reduced the response to 3-mercapto-2-methylpentan-1-ol by half (Fig. 1a, Fig. S6e, f, Table S6). We observed a complete loss-of-function in the presence of $\mathrm{Zn}^{2+}$ (Fig. 1a, Fig. S6 g, Table S6). We observed the largest potentiating effects under supplementation with ionic or colloidal silver, which led to a three-to-sixfold increase in amplitude for OR2M3 and 3-mercapto-2-methylpentan-1-ol (Fig. 1a, Fig. S6 h-j, Table S6), suggesting particularly strong ligand/sulfur-silver interactions within the receptor.

We next tested for the optimal $\mathrm{Cu}^{2+}$ concentration. As originally suggested by Crabtree [27], the active form of copper involved in ligand coordination is likely $\mathrm{Cu}^{1+}$ due to the naturally reducing environment in cells. Therefore, $\mathrm{Cu}^{2+}$ added in our experiments was likely reduced to $\mathrm{Cu}^{1+}$. We found that adding $\mathrm{Cu}^{2+}$ at a concentration of $10 \mu \mathrm{mol} / \mathrm{L}$ gave the highest potentiation of 3-mercapto-2-methylpentan-1ol's efficacy in activating OR2M3, which was about fourfold increased as compared to control conditions without $\mathrm{Cu}^{2+}$ supplementation (Fig. 1c, d, Fig. S7, Table S7). Importantly, supplementation with $\mathrm{Cu}^{2+}>10 \mu \mathrm{mol} / \mathrm{L}$ decreased both 3-mercapto-2-methylpentan-1-ol-induced receptor signaling as well as odorant-independent constitutive activity of OR2M3 (Fig. 1c). $\mathrm{Cu}^{2+}$ supplementation of $10 \mu \mathrm{mol} / \mathrm{L}$, however, did not inhibit a basal activity of OR2M3 (Fig. 1c), and was, therefore, used in all experiments testing a potentiating effect of copper throughout the present study. $\mathrm{Cu}^{2+}$ at $10 \mu \mathrm{mol} / \mathrm{L}$ had little effect on the $\mathrm{EC}_{50}$ value of 3-mercapto2-methylpentan-1-ol on OR2M3 (Table 1). Notably, the receptor/agonist pair OR2M3/3-mercapto-2-methylpentan1-ol when measured in the absence of copper showed a Hill coefficient of $0.89 \pm 0.41(n=4)$, whereas in the presence of copper $(10 \mu \mathrm{mol} / \mathrm{L})$, the Hill coefficient increased about twofold to $1.93 \pm 0.71(n=4)$.

In contrast to the potentiating effect of $\mathrm{Cu}^{2+}$ on OR2M3, the efficacy of 2-phenylethanethiol in activating OR1A1 was reduced in the presence of $\mathrm{Cu}^{2+}$ at $10 \mu \mathrm{mol} / \mathrm{L}$ (Fig. 2a, Table 1). Indeed, the $E C_{50}$ value of 2-phenylethanethiol on OR2W1 was increased in the presence of $\mathrm{Cu}^{2+}$, indicating a lower potency of 2-phenylethanethiol in activating broadly tuned OR2W1 (Fig. 2b, Table 1). $\mathrm{Cu}^{2+}$ at $10 \mu \mathrm{mol} / \mathrm{L}$ did not affect the concentration-response relations of two KFO thiol agonists of broadly tuned OR2W1, 2-phenylethanethiol, or 3-mercaptohexyl acetate, or its non-thiol agonist allyl phenyl acetate (Fig. 2b, d, f, Table 1). Likewise, the presence of $\mathrm{Cu}^{2+}$ affected neither the activation of broadly tuned OR1A1 by its thiol agonist 3-mercaptohexyl acetate (Fig. 2c, Table 1) nor by $(R)-(-)$-carvone (Fig. 2e, Table 1). Also, the activation of NxG $108 \mathrm{CC} 15$-endogenous adenosine receptors A2A/A2B [52] or sphingosine-1-phosphate receptor 4 (S1P4) receptors by their respective agonists was not affected by copper supplementation (Fig. 2g, h, Table 1).

\section{Cys179 of the HxxC[DE]-Motif in ECL 2 of ORs plays a copper-independent role for a receptor function}

To challenge the hypothesis of a metal-coordinating role of the HxxC[DE] motif of ECL 2 in the majority of ORs posed by Wang et al. [28], we established variants of OR2M3 and OR2W1, changing the conserved cysteine at position 179 to an alanine by site-directed mutagenesis. For OR2M3, we further established the variant OR2M3 $\mathrm{C}_{179} \mathrm{Y}$, which was described as single-nucleotide polymorphism (SNP) [85], and a variant where we changed the cysteine to a serine. Already in the absence of any copper supplementation, all of these receptor variants displayed a complete loss-of function when tested with their respective agonists (Fig. 3b-e), suggesting a rather general role of at least Cys179 for the tertiary structure of ORs [86-88].
Table $1 \mathrm{EC}_{50}$ values for wildtype receptors in the absence and presence of $10 \mu \mathrm{mol} / \mathrm{L} \mathrm{Cu}^{2+}$

\begin{tabular}{|c|c|c|c|}
\hline Receptor & Agonist & $\begin{array}{l}\mathrm{EC}_{50} \text { in the absence of } \\
\mathrm{Cu}^{2+} \text { in } \mu \mathrm{mol} / \mathrm{L}^{\mathrm{a}}\end{array}$ & $\begin{array}{l}\mathrm{EC}_{50} \text { in the presence } \\
\text { of } \mathrm{Cu}^{2+} \text { in } \mu \mathrm{mol} / \mathrm{L}^{\mathrm{a}}\end{array}$ \\
\hline OR2M3 $\mathrm{wt}$ & 3-Mercapto-2-methylpentan-1-ol & $0.45 \pm 0.19$ & $0.29 \pm 0.10$ \\
\hline OR2W1 wt & 2-Phenylethanethiol & $37.81 \pm 0.62$ & $106.21 \pm 0.93$ \\
\hline $\mathrm{OR} 2 \mathrm{~W} 1 \mathrm{wt}$ & 3-Mercaptohexyl acetate & $132.10 \pm 20.86$ & $120.78 \pm 1.59$ \\
\hline OR2W1wt & Allyl phenyl acetate & $64.40 \pm 3.58$ & $55.15 \pm 8.59$ \\
\hline OR1A1 wt & $(R)$-(-)-Carvone & $126.47 \pm 34.07$ & $159.03 \pm 43.09$ \\
\hline OR1A1 wt & 2-Phenylethanethiol & $205.94 \pm 21.53$ & $73.06 \pm 16.35$ \\
\hline OR1A1 wt & 3-Mercaptohexyl acetate & $404.65 \pm 86.73$ & $353.78 \pm 113.08$ \\
\hline $\mathrm{A} 2 \mathrm{~A} / \mathrm{A} 2 \mathrm{~B}$ & Adenosine & $471.75 \pm 35.10$ & $452.95 \pm 38.26$ \\
\hline $\mathrm{S} 1 \mathrm{P} 4^{\mathrm{b}}$ & CYM50308 & $516.51 \pm 74.57$ & $343.76 \pm 91.02$ \\
\hline
\end{tabular}

${ }^{\mathrm{a}} \mathrm{Mean} \pm \mathrm{SD}(n=3-5)$

${ }^{\mathrm{b}} E C_{50}$ in $\mathrm{nmol} / \mathrm{L}$ 
Fig. $2 \mathrm{Cu}^{2+}$ diminished the efficacy or potency of 2-phenylethanethiol of broadly tuned OR1A1 and OR2W1, but not of 3-mercaptohexyl acetate or nonthiol receptor agonists. Effects of $10 \mu \mathrm{mol} / \mathrm{L} \mathrm{Cu}^{2+}$ on the concentration-response relations of thiol and non-thiol agonists of OR1A1 (a, c, e), OR2W1 (b, d, f), and endogenously expressed GPCRs, adenosine receptors A2A/A2B (g), and sphingosine1-phosphate receptor 4, S1P4 (h). Data were mock controlsubtracted, normalized to each receptor maximum amplitude as response to the respective substance measured in the absence of $\mathrm{Cu}^{2+}$, and shown as mean $\pm \mathrm{SD}(n=3-6)$. $R L U$ relative luminescence unit. Curves represent best fits to the data in the absence (black) or presence (blue) of $\mathrm{Cu}^{2+}$, with $\mathrm{EC}_{50}$ values given in Table 1 a

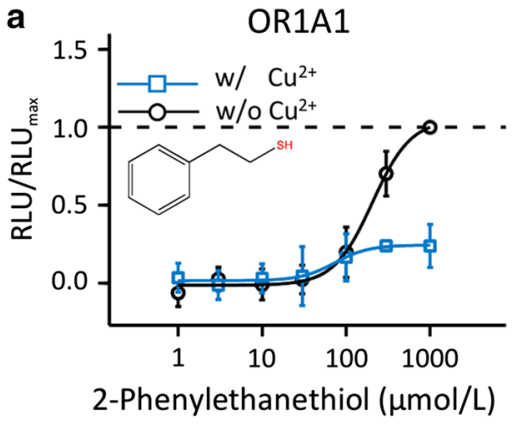

C

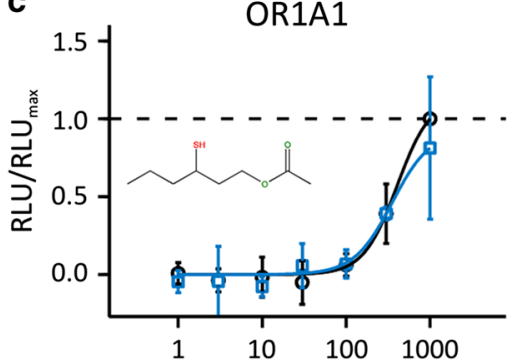

3-Mercaptohexyl acetate ( $\mu \mathrm{mol} / \mathrm{L})$

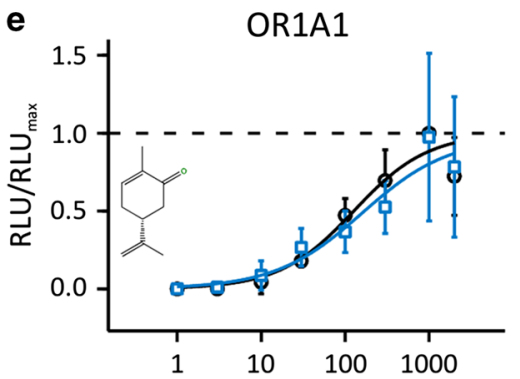

$(R)-(-)$-Carvone $(\mu \mathrm{mol} / \mathrm{L})$

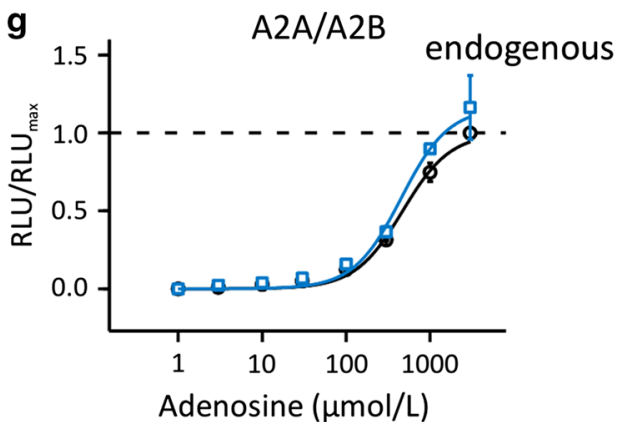

b

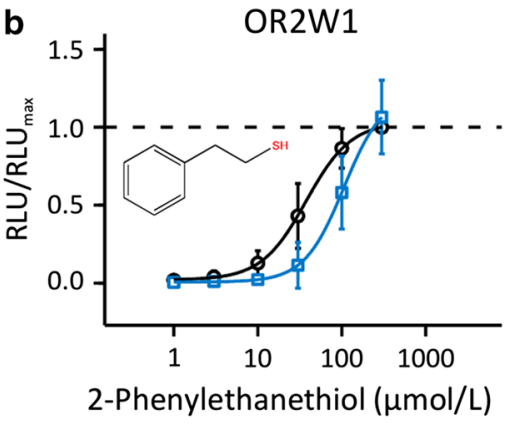

d

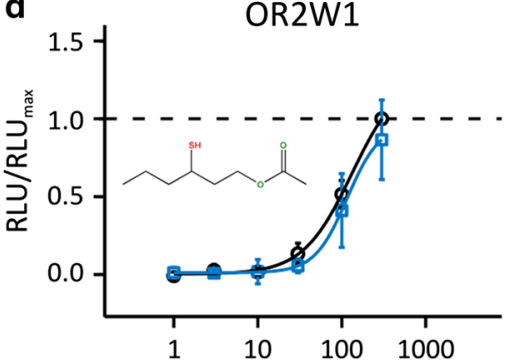

3-Mercaptohexyl acetate $(\mu \mathrm{mol} / \mathrm{L})$

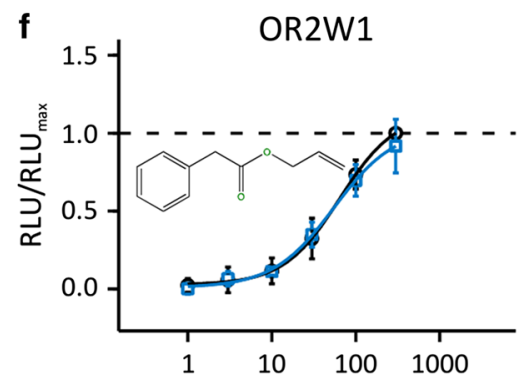

Allyl phenyl acetate ( $\mu \mathrm{mol} / \mathrm{L})$

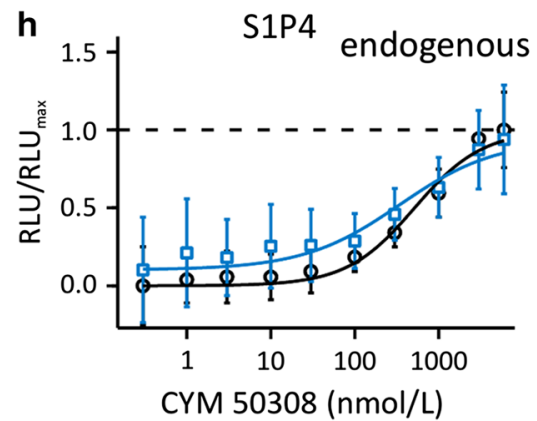

TMH 5 and TMH 6 of OR2M3 harbor cysteines necessary for a potentiating effect of $\mathrm{Cu}^{2+}$ on 3-mercapto-2-methylpentan-1-ol function in OR2M3

Sekharan et al. [30] showed with their QM/MM model and mutagenesis-guided functional experiments that copper supposedly binds to His $105^{3.33}$, Cys $109^{3.37}$, and Asn202 $2^{5.42}$ in an internal aqueous channel of Olfr1509 (MOR244-3). They proposed Cys $109^{3.37}$ of Olfr1509 to coordinate the copper ion in the receptor [30]. Based on the QM/MM model by Sekharan et al. [30], we prepared variants of OR2M3 by changing the respective amino acids of OR2M3 to the amino acids of Olfr 1509 at the positions $105^{3.33}$ and $109^{3.37}$. Moreover, we prepared SNP-based haplotypes: For position $105^{3.33}$, we changed the threonine to an isoleucine or to an alanine. Both, however, have a minor allele frequency (MAF) of only 0.008 [89]. Furthermore, we changed the glycine at position $109^{3.37}$ to an arginine [85]. Since cysteine contains an $\mathrm{S}$ atom and is a polar amino acid, its free thiol 


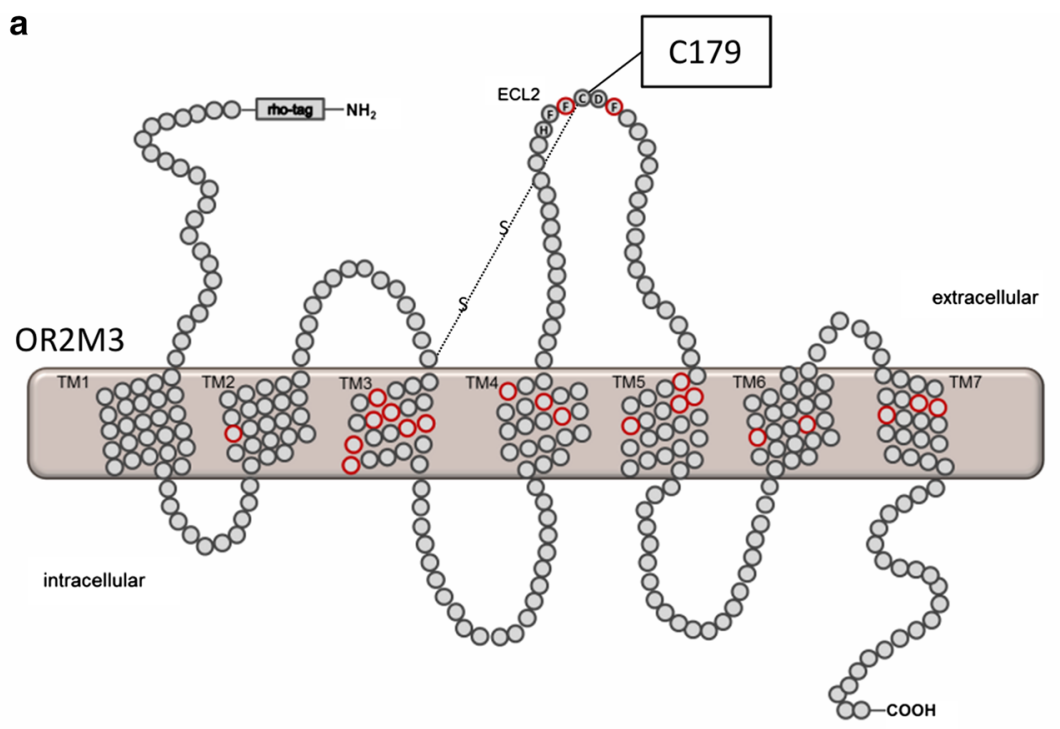

b

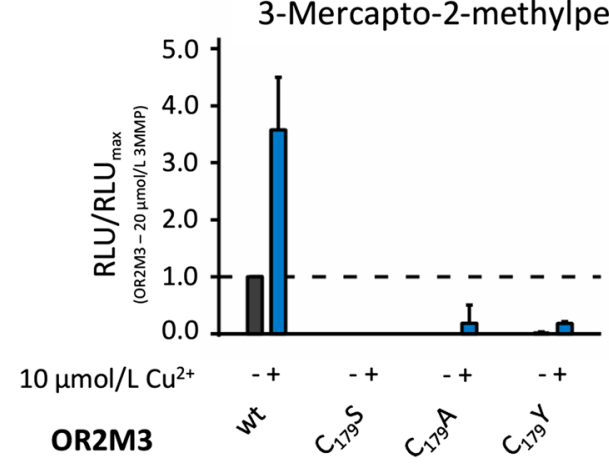

Fig. 3 Mutating the conserved cysteine in the HxxC[DE]-motif (Wang et al. [28]) abolishes odorant responses of ORs independent of $\mathrm{Cu}^{2+}$. a Schematic snake diagram of OR2M3 with localization of amino acid position Cys179 within the HxxC[DE]-motif of ECL 2. Putative odorant interaction sites proposed by Man et al. [85] are given as red circles. b Effects of different Cys179 mutations in OR2M3, tested with 3-mercapto-2-methylpentan-1-ol $(20 \mu \mathrm{mol} / \mathrm{L})$,

group can build $\mathrm{S}-\mathrm{S}$ bonds after oxidation. Furthermore, the binding of copper or other metal ions such as zinc and iron often occurs at cysteine residues in metalloproteins [90-93]. Therefore, and since Cys $112^{3.40}$ is in the vicinity of positions $105^{3.33}$ and $109^{3.37}$, we exchanged Cys $112^{3.40}$ to a serine or an alanine.

We found that all OR variants with mutations at position $105^{3.33}, 109^{3.37}$, or $112^{3.40}$ were not functional anymore (Fig. 4b). However, the presence of copper $10 \mu \mathrm{mol} / \mathrm{L}$ rescued 3-mercapto-2-methylpentan-1-ol function in OR2M3, at least for mutations $\mathrm{T}_{105} \mathrm{~A}, \mathrm{C}_{112} \mathrm{~A}$, and $\mathrm{C}_{112} \mathrm{~S}$ (Fig. 4b, Fig $\mathrm{S} 8 \mathrm{a}, \mathrm{b}$, and Table 2). This suggested that other positions in OR2M3 were involved in a copper interaction.

Zhang et al. [32] showed for the murine receptor Olfr 1019 that Cys $203^{5.42}$ is involved in binding copper.
C

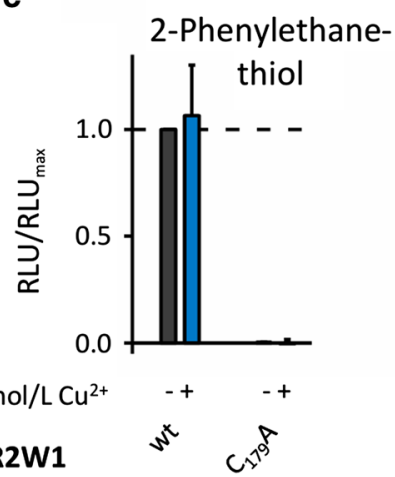

d 3-Mercaptohexylacetate

e

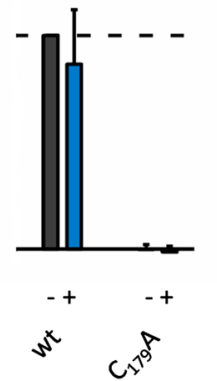

Allyl phenyl acetate

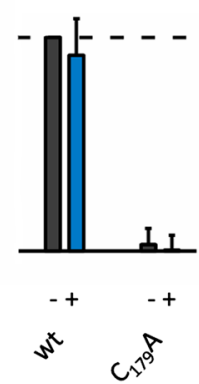

and compared to the wild-type (wt) receptor. (c-e) Effects of thiol and non-thiol agonists $\left(300 \mu \mathrm{mol} / \mathrm{L}\right.$, each) on OR2W1 $\mathrm{C}_{179} \mathrm{~A}$. Data were recorded in the absence (black) or presence (blue) of $\mathrm{Cu}^{2+}$, normalized to the respective wt signal in the absence of $\mathrm{Cu}^{2+}$, and represented as mean $\pm \mathrm{SD}(n=3)$. $R L U$ relative luminescence unit, 3MMP 3-mercapto-2-methylpentan-1-ol

OR2M3 contains two adjacent cysteines at positions $202^{5.41}$ and $203^{5.42}$. We, therefore, changed these cysteines to either an alanine or to a serine. OR2M3 variants carrying mutations $\mathrm{C}_{202} \mathrm{~A}, \mathrm{C}_{202} \mathrm{~S}$, or $\mathrm{C}_{203} \mathrm{~A}$ revealed a complete lossof-function, even in the presence of $\mathrm{Cu}^{2+}$, with a strongly diminished 3-mercapto-2-methylpentan-1-ol function in $\mathrm{C}_{203} \mathrm{~A}$ (Fig. 4b, Fig. S8c, and Table 2).

We further investigated a putative functional role of the cysteines at positions $202^{5.41}$ and $203^{5.42}$ in OR2M3. Indeed, at least position $203^{5.42}$ aligns with a putative odorant-binding pocket suggested by Man et al. [88]. Furthermore, we investigated the haplotype with one SNP, OR2M3 $\mathrm{C}_{203} \mathrm{Y}$, which has an MAF of $<0.01$ [89]. In our hands, OR2M $3 \mathrm{C}_{203} \mathrm{Y}$ showed a complete loss-of-function, in the absence or presence of $\mathrm{Cu}^{2+}$. Altogether, our results 
Fig. 4 Testing amino acid positions of proposed copper/odorant-binding pockets [30-32] by site-directed mutagenesis in OR2M3. a Schematic snake diagram of OR2M3 with localization of mutated amino acid positions within TMH 3-6. Putative odorant interaction sites proposed by Man et al. [85] are given as red circles. $\mathbf{b}$ Effect of 3-mercapto-2-methylpentan1-ol $(20 \mu \mathrm{mol} / \mathrm{L})$ on OR2M3 mutants, in the absence (black) or presence (blue) of $\mathrm{Cu}^{2+}$. Data were normalized to the OR2M3 wt signal in response to 3-mercapto-2-methyl-pentan1 -ol $(20 \mu \mathrm{mol} / \mathrm{L})$, measured in the absence of $\mathrm{Cu}^{2+}$. Shown are mean $\pm \mathrm{SD}(n=3)$. $R L U$ relative luminescence unit, $3 M M P$ 3-mercapto-2-methylpentan1-ol. Concentration-response curves for all mutant receptors are given in Supplemental Figure $\mathrm{S} 8$, and $\mathrm{EC}_{50}$ values are given in Table 2

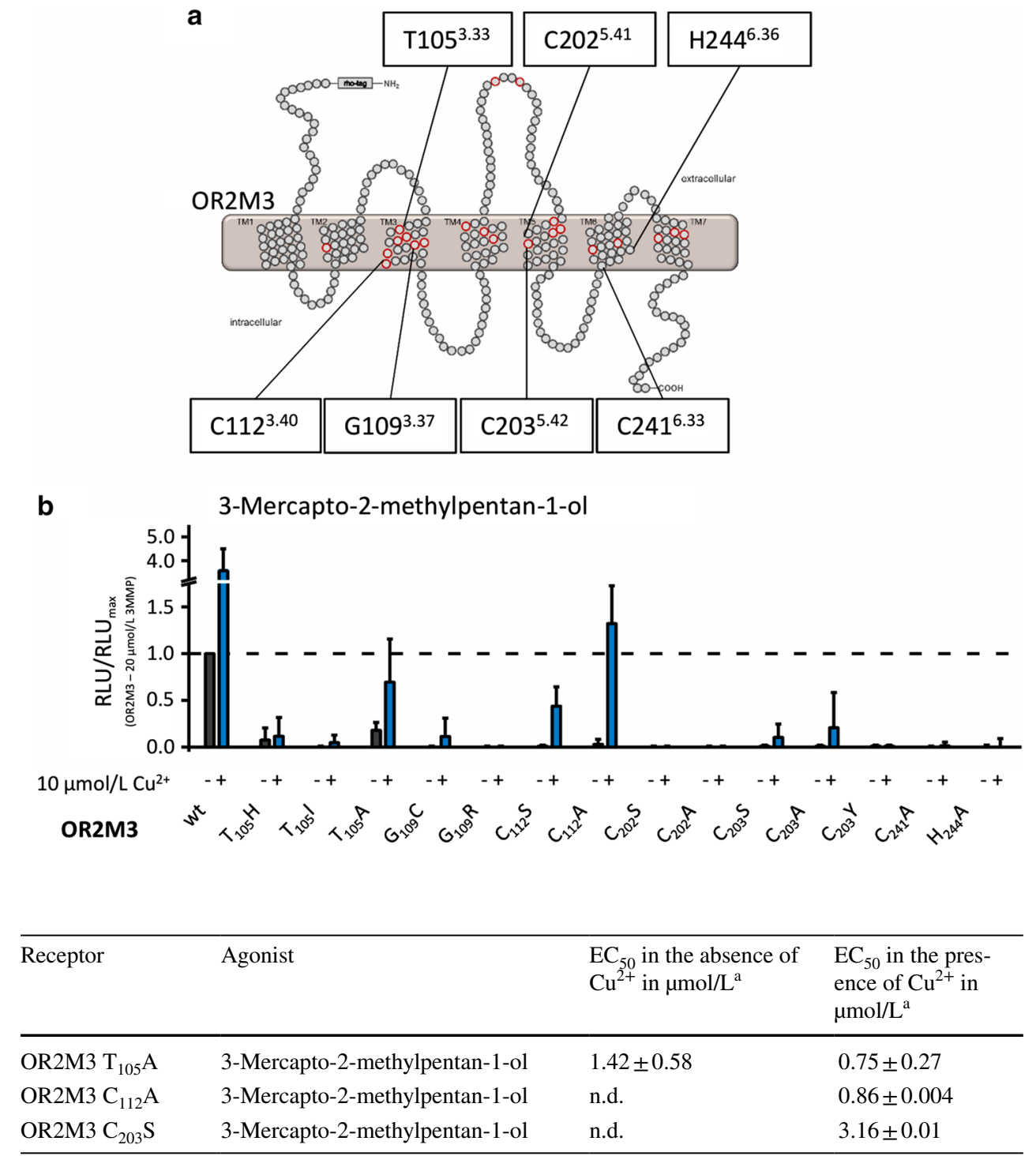

b

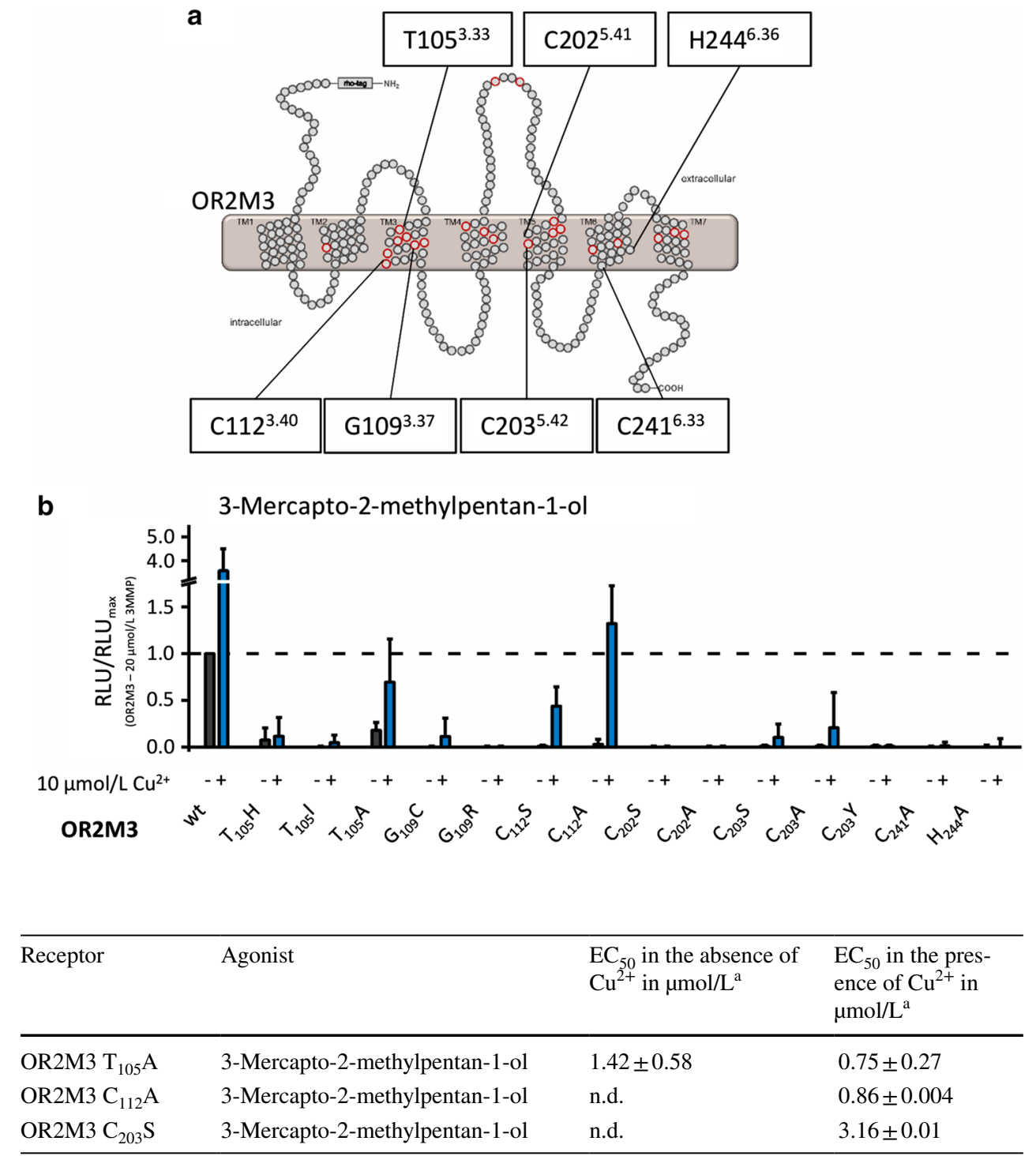

\begin{tabular}{llll}
\hline Receptor & Agonist & $\begin{array}{l}\mathrm{EC}_{50} \text { in the absence of } \\
\mathrm{Cu}^{2+} \text { in } \mu \mathrm{mol} / \mathrm{L}^{\mathrm{a}}\end{array}$ & $\begin{array}{l}\mathrm{EC}_{50} \text { in the pres- } \\
{\mathrm{ence} \mathrm{of} \mathrm{Cu}^{2+} \text { in }}_{\mu \mathrm{mol} / \mathrm{L}^{\mathrm{a}}}\end{array}$ \\
\hline OR2M3 T $\mathrm{T}_{105} \mathrm{~A}$ & 3-Mercapto-2-methylpentan-1-ol & $1.42 \pm 0.58$ & $0.75 \pm 0.27$ \\
OR2M3 $\mathrm{C}_{112} \mathrm{~A}$ & 3-Mercapto-2-methylpentan-1-ol & n.d. & $0.86 \pm 0.004$ \\
OR2M3 $\mathrm{C}_{203} \mathrm{~S}$ & 3-Mercapto-2-methylpentan-1-ol & n.d. & $3.16 \pm 0.01$ \\
\hline
\end{tabular}

n.d. no detectable response up to $100 \mu \mathrm{mol} / \mathrm{L}$

${ }^{\mathrm{a}} \mathrm{Mean} \pm \mathrm{SD}(n=3-5)$
Table $2 E C_{50}$ values for OR2M3 with amino acid changes at positions of a putative copper/odorant-binding pocket measured in the absence and presence of $10 \mu \mathrm{mol} / \mathrm{L} \mathrm{Cu}^{2+}$ suggest both positions Cys202 2.41 and Cys $203^{5.42}$ to be necessary for a potentiating effect of $\mathrm{Cu}^{2+}$ on a 3-mercapto2-methylpentan-1-ol function in OR2M3.

Our concentration-response relation of 3-mercapto2-methylpentan-1-ol on OR2M3 wt in the presence of $\mathrm{Cu}^{2+}$ revealed a Hill coefficient close to 2 (see Fig. 1d), suggesting positive cooperativity of at least two binding sites for $\mathrm{Cu}^{2+}$ and/or 3-mercapto-2-methylpentan-1-ol. Indeed, within copper-dependent human OR2T11, two distinct copperbinding sites have been reported previously, constituted by

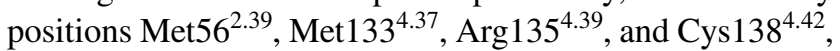
and positions Met115 $5^{3.46}$, Cys238 $8^{6.33}$, and His241 ${ }^{6.36}$ [31]. Positions Cys $238^{6.33}$ and His $241^{6.36}$ in OR2T11 correspond to positions Cys $241^{6.33}$ and His $244^{6.36}$ in OR2M3, respectively. Since positions Cys238 ${ }^{6.33}$ and His $241^{6.36}$ are part of the putative copper-binding CSSH(L) motif in OR2T11, which is close to the cytoplasmic region, similar to other candidate pentapeptides previously proposed for metalbinding sites at the end of TMH 6 [34], we mutated the corresponding positions Cys $241^{6.33}$ and His $244^{6.36}$ in OR2M3 by changing the respective amino acids to an alanine. In our hands, both OR2M3 variants were not functional anymore, in the absence or presence of $\mathrm{Cu}^{2+}$ (Fig. 4b), suggesting both positions to be necessary for a potentiating effect of $\mathrm{Cu}^{2+}$ on a 3-mercapto-2-methylpentan-1-ol function in OR2M3. 


\section{SNPs in close vicinity of predicted copper/ odorant-binding positions affected the 3-mercapto-2-methylpentan-1-ol function of OR2M3}

Previously, Man et al. [88] determined 22 amino acid positions, which constitute a putative, generalized, and conserved odorant-binding pocket within OR orthologs. We, therefore, investigated the effects of three SNPs that occur in the putative binding pocket of OR2M3 near proposed copper-interacting positions [30], by testing these haplotypes against 3-mercapto-2-methylpentan-1-ol in the GloSensor ${ }^{\mathrm{TM}}$ assay (Fig. S9). For the variant, OR2M3 $\mathrm{M}_{206} \mathrm{I}$, we observed a complete loss-of-function (Fig. S9c). Compared to OR2M3 wt, OR2M3 $\mathrm{Y}_{104} \mathrm{C}$ displayed a gain of function with respect to the amplitude but a higher $E C_{50}$ value $\left(1.02 \pm 0.18 \mu \mathrm{mol} / \mathrm{L}\right.$, Fig. S9b), whereas OR2M3 $\mathrm{I}_{207} \mathrm{~L}$ had a diminished amplitude and a higher $E C_{50}$ value $(1.41 \pm 0.04$, Fig. S9d). All SNPs in OR2M3, however, have either no reported MAF, or a rather low MAF $(<0.01)$.
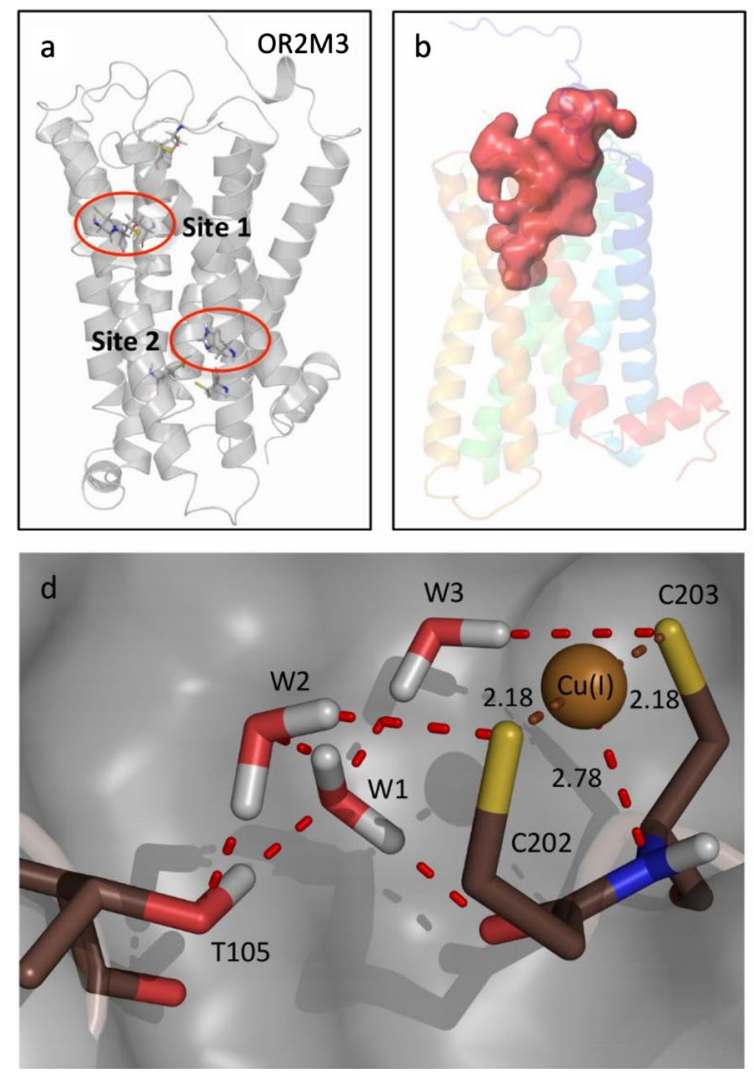

Fig. 5 Molecular modeling reveals two 3-mercapto-2-methylpentan1-ol/copper-binding sites within OR2M3. a Binding sites within the homology model of OR2M3, involving TMH 3 and TMH 5 (site 1) or TMH 3 and TMH 6 (site 2). b Accessible volume of the ligand

\section{Homology modeling and QM/MM studies revealed two copper-coordinating sites within narrowly tuned OR2M3}

Figure 5a shows the structural model of OR2M3 obtained using the X-ray crystal structure of the human M1 muscarinic receptor as a template (5CXV.pdb) [63]. The homology model provides valuable insights on the proposed odorant-binding site, including a highly conserved disulfide $\mathrm{S}-\mathrm{S}$ bond thought to be critical for structural stability. The structural model of OR2M3 shows that the disulfide bond forms between Cys97 $97^{3.25}$ of TMH 3 and Cys179 of extracellular loop 2 (ECL 2) (Fig. 5a). Two binding sites for $\mathrm{Cu}(\mathrm{I})$ were identified in OR2M3 (Fig. 5, Fig. S10). The binding sites are supported by site-directed mutagenesis and activation profiles, showing a lack of response to ligand when mutating the key amino acid residues responsible for copper binding (Fig. S10).

The first ligand/copper-binding site (site 1) shares similarities with the copper-binding site suggested for Olfr 1509 (MOR244-3) [30] with one $\mathrm{Cu}(\mathrm{I})$ bound to His105 13.33 ,
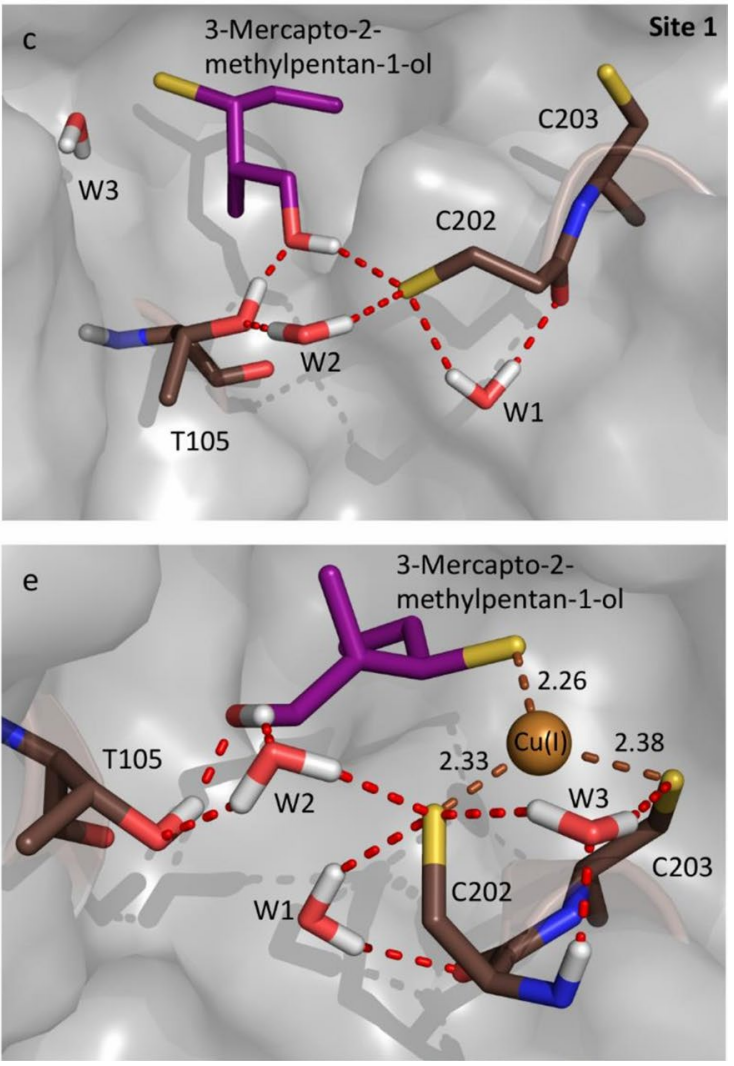

in OR2M3 (site 1). QM/MM structural model of site 1 in OR2M3 with the ligand 3-mercapto-2-methylpentan-1-ol (c), with $\mathrm{Cu}(\mathrm{I})(\mathbf{d})$, or both (e). Residues defining the binding pocket are shown as sticks (oxygen: red; nitrogen: blue; sulfur: yellow) 
Cys $109^{3.37}$, and Asn202 2.42 ; the copper-binding site in Olfr1509 is close to the extracellular domain. In contrast, OR2M3 involves two binding sites. Site 1 has an accessible volume of $695.26 \AA^{3}$ for 3-mercapto-2-methylpentan-1-ol (Fig. 5b), and involves Thr $105^{3.33}$ of TMH 3, and residues Cys202 $2^{5.41}$ and Cys203 $3^{5.42}$ from TMH 5 (Fig. 5c). The $\mathrm{Cu}(\mathrm{I})_{\mathrm{S} 1}$ ion has a trigonal planar configuration with $\mathrm{S}_{\mathrm{C} 202}$, $\mathrm{S}_{\mathrm{C} 203}$ and a weak interaction with $\mathrm{N}_{\mathrm{C} 203}$, with distances of $2.18 \AA, 2.18 \AA$ and $2.78 \AA$, respectively, as shown in Fig. 5d, which indicates the QM/MM structural model for OR2M3. It is also important to note that water molecules form hydrogen bonds with residues Thr $105^{3.33}$, Cys202 $2^{5.41}$, and Cys $203^{5.42}$. For example, the water molecule (W1) forms hydrogen bonds $\mathrm{O}_{\mathrm{C} 202}-\mathrm{HO}_{\mathrm{W} 1}$ and $\mathrm{OH}_{\mathrm{T} 105}-\mathrm{O}_{\mathrm{W} 1}$ with distances of $1.88 \AA$ and $1.79 \AA$, respectively. Another water molecule (W2) is also located between residues Thr $105^{3.33}$ and Cys $202^{5.41}$, forming hydrogen bonds $\mathrm{HO}_{\mathrm{T} 105}-\mathrm{HO}_{\mathrm{W} 2}$ and $\mathrm{S}_{\mathrm{C} 202}-\mathrm{HO}_{\mathrm{W} 2}$, with distances of $2.05 \AA$ and $2.31 \AA$, respectively. $\mathrm{HO}_{\mathrm{w} 1}-\mathrm{O}_{\mathrm{W} 2}$ forms an $\mathrm{H}$-bond with a distance of $1.85 \AA$. The third water molecule (W3) form hydrogen bonds $\mathrm{S}_{\mathrm{C} 203}-\mathrm{HO}_{\mathrm{W} 3}$ and $\mathrm{O}_{\mathrm{w} 1}-\mathrm{HO}_{\mathrm{w} 3}$ with distances of $2.49 \AA$ and $2.00 \AA$, respectively.

Upon ligand (3-mercapto-2-methylpentan-1-ol) binding, the active sites undergo coordination rearrangements. Figure 5e shows the QM/MM structure of the binding site with the ligand. At site 1 , the $\mathrm{Cu}(\mathrm{I})_{\mathrm{S} 1}$ ion has trigonal planar geometry with the $\mathrm{S}$ (thiolate form) of ligand, $\mathrm{S}_{\mathrm{C} 202}$ and $\mathrm{S}_{\mathrm{C} 203}$. The distances between $\mathrm{Cu}(\mathrm{I})_{\mathrm{s} 1}$ and $\mathrm{S}$ (thiolate forms) of the ligand, $\mathrm{S}_{\mathrm{C} 202}$ and $\mathrm{S}_{\mathrm{C} 203}$ are $2.26 \AA, 2.33 \AA$, and $2.38 \AA$, respectively. The distance between the $\mathrm{Cu}(\mathrm{I})_{\mathrm{S} 1}$ ion and $\mathrm{N}_{\mathrm{C} 203}$ elongated to $3.14 \AA$ from $2.78 \AA$. While the $\mathrm{S}$ atom of the ligand coordinates with $\mathrm{Cu}(\mathrm{I})$, the ligand $\mathrm{O}$ (alcoholic) forms a strong H-bond with the $\mathrm{HO}$ of $\mathrm{Thr} 105^{3.33}$ with the distance of $1.80 \AA$, which elongates $\mathrm{OH}_{\mathrm{T} 105}-\mathrm{O}_{\mathrm{W} 1} \mathrm{H}$-bond. We also find that water molecule $\mathrm{W} 1$ forms a new but weak H-bond with Cys202 $2^{5.41}, \mathrm{~S}_{\mathrm{C} 202}-\mathrm{HO}_{\mathrm{W} 1}$, with a distance of $2.38 \AA$.

Moreover, $\mathrm{HO}_{\text {ligand }}$ also shows a strong $1.88 \AA \mathrm{H}$-bond with $\mathrm{O}_{\mathrm{w} 2}$. These new H-bond formations slightly displace water molecule $\mathrm{W} 2$ towards residue Cys202 $2^{5.41}$, with a $2.25 \AA \mathrm{S}_{\mathrm{C} 202}-\mathrm{HO}_{\mathrm{W} 2}$ distance. However, the $\mathrm{HO}_{\mathrm{T} 105}-\mathrm{HO}_{\mathrm{W} 2}$ distance did not change upon ligand binding. Like W2, W3 also moves towards the residues Cys202 2.41 and Cys203 $3^{5.42}$, forming new $\mathrm{S}_{\mathrm{C} 203}-\mathrm{HO}_{\mathrm{W} 3}$ and $\mathrm{O}_{\mathrm{W} 3}-\mathrm{HN}_{\mathrm{C} 202} \mathrm{H}$-bonds with respective distances of $2.35 \AA$ and $1.99 \AA$.

The second binding site (site 2 ) includes residues Met $118^{3.46}$ of TMH 3, His244 $4^{6.36}$, Cys $241^{6.33}$ of TMH 6, and a water molecule (W4) (Fig. S10a). Unlike site 1, Cu(I) $)_{\mathrm{S} 2}$ ion forms a tetrahedral configuration with $\mathrm{S}_{\mathrm{M} 118}, \mathrm{~S}_{\mathrm{C} 241}$, $\mathrm{N}_{\mathrm{H} 244}$, and $\mathrm{O}_{\mathrm{W} 4}$ with distances of $2.41 \AA$, $2.16 \AA, 2.00 \AA$, and $2.36 \AA$, respectively (Fig. S10b). Water molecule W4 also shows an $\mathrm{H}$-bond $\left(\mathrm{N}_{\mathrm{C} 241}-\mathrm{HO}_{\mathrm{W} 4}\right)$ with a distance of $2.18 \AA$ A. Upon ligand binding at site $2, \mathrm{Cu}(\mathrm{I})_{\mathrm{S} 2}$ accommodates a distorted tetrahedral geometry with $\mathrm{S}_{\text {ligand }}, \mathrm{S}_{\mathrm{C} 241}$,
$\mathrm{N}_{\mathrm{H} 244}$, and $\mathrm{O}_{\mathrm{W} 4}$ with distances of $2.29 \AA$, $2.18 \AA$, $2.02 \AA$, and $3.06 \AA$, respectively (Fig. S8c). The distance of the residue Met118 3.46 and $\mathrm{Cu}$ ion extends to $4.54 \AA$ from $2.41 \AA$. A strong $\mathrm{H}$-bond is also observed between $\mathrm{OH}_{\text {ligand }}$ and $\mathrm{O}_{\mathrm{W} 4}$ with a distance of $1.98 \AA$. In addition, the water W4 shows a weak H-bond interaction with the $\mathrm{S}$ (thiolate) of the ligand by the distance of $2.21 \AA$.

\section{Modeling did not support evidence for a putative copper-binding site within the broadly tuned OR2W1}

Sekharan et al. [30] proposed Cys $109^{3.37}$ of Olfr1509 to coordinate the copper ion in the receptor [30]. To investigate if we can induce a copper-enhancing effect also in OR2W1, we changed the respective amino acids of OR2W1 to the amino acids of Olfr1509 at the positions $105^{3.33}$ and $109^{3.37}$. We performed the point mutation OR2W1 $\mathrm{M}_{105} \mathrm{H}$, because histidine can act as a ligand of metal ion complexes and possibly can induce a copper-enhancing effect in OR2W1. We observed, however, a loss-of-function with all three tested ligands, suggesting that histidine prevents the formation of the functionally active network of contact sites in OR2W1 (Fig. 6b-d).

We then tried to induce a copper-enhancing effect by introducing a cysteine at position $109^{3.37}$. Again, we observed a loss-of function with all three tested ligands (Fig. 6b-d). Nevertheless, introducing an alanine at position $109^{3.37}$, the OR2W1 variant $\mathrm{S}_{109} \mathrm{~A}$ was still functional, but displayed agonist-specific and $\mathrm{Cu}^{2+}$-dependent differences in potency and efficacy (Fig. 6 b-d, Fig. S8j-1, Table 3). Since the free thiol group of cysteine can build S-S bonds, we further investigated Cys $112^{3.40}$ in OR2W1 and exchanged the cysteine for an alanine. OR2W1 $\mathrm{C}_{112} \mathrm{~A}$ did not respond to one of its agonists, in the absence or presence of $\mathrm{Cu}^{2+}$ (Fig. 6b-d).

Our results so far suggested that in OR2M3, two cysteines at positions $202^{5.41}$ and $203^{5.42}$ coordinate copper in the ligand-binding pocket. Similarly, Cys $203^{5.42}$ has recently been shown to be involved in copper binding in Olfr1019 [32]. OR2W1, however, lacks cysteines at these positions. We, therefore, tested whether cysteines at positions $202^{5.41}$ and $203^{5.42}$ will introduce a copper-dependent ligand response in OR2W1. When changing the leucine at position $202^{5.41}$ to a cysteine or to a serine, in our hands, both OR2W1 variants $\mathrm{L}_{202} \mathrm{~S}$ or $\mathrm{L}_{202} \mathrm{C}$ were still functional, but displayed agonist-specific and $\mathrm{Cu}^{2+}$-dependent differences in potency and efficacy (Fig. 6b-d).

For 2-phenylethanethiol, both $\mathrm{OR} 2 \mathrm{~W} 1 \mathrm{~L}_{202} \mathrm{~S}$ and OR2W1 $\mathrm{L}_{202} \mathrm{C}$ displayed lower amplitudes in the presence of $\mathrm{Cu}^{2+}$, as compared to OR2W1 wt (Fig. 6b), and a lower potency (Fig. S8d, g, Table 3), although both potency and efficacy of 2-phenylethanethiol were already diminished in 
Fig. 6 Testing amino acid positions of proposed copper/odorant-binding pockets [30-32] by site-directed mutagenesis in OR2W1. a Schematic snake diagram of OR2W1 with localization of mutated amino acid positions within TMH 3-6. Putative odorant interaction sites proposed by Man et al. [85] are given as red circles. Effect of 2-phenylethanethiol (300 $\mu \mathrm{mol} / \mathrm{L})(\mathbf{b}), 3$-mercaptohexyl acetate $(300 \mu \mathrm{mol} / \mathrm{L})$ (c), and allyl phenyl acetate $(300 \mu \mathrm{mol} / \mathrm{L})(\mathbf{d})$ on OR2W1 mutants in the absence (black) or presence (blue) of $\mathrm{Cu}^{2+}$. Data were mock control-subtracted, normalized to the OR2W1 wt signal of each ligand, measured in the absence of $\mathrm{Cu}^{2+}$, and displayed as mean $\pm \operatorname{SD}(n=3)$. $R L U$ relative luminescence unit, 2PHE 2-phenylethanethiol, 3MAc 3-mercaptohexyl acetate, $A P A c$ allyl phenyl acetate. Concentration-response curves for all mutant receptors are given in Supplemental Figure S8, and $\mathrm{EC}_{50}$ values are given in Table 3 a

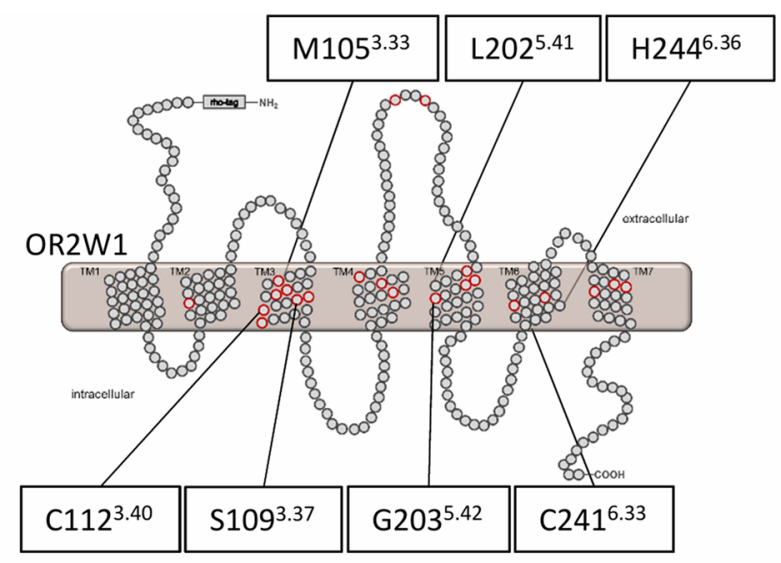

b

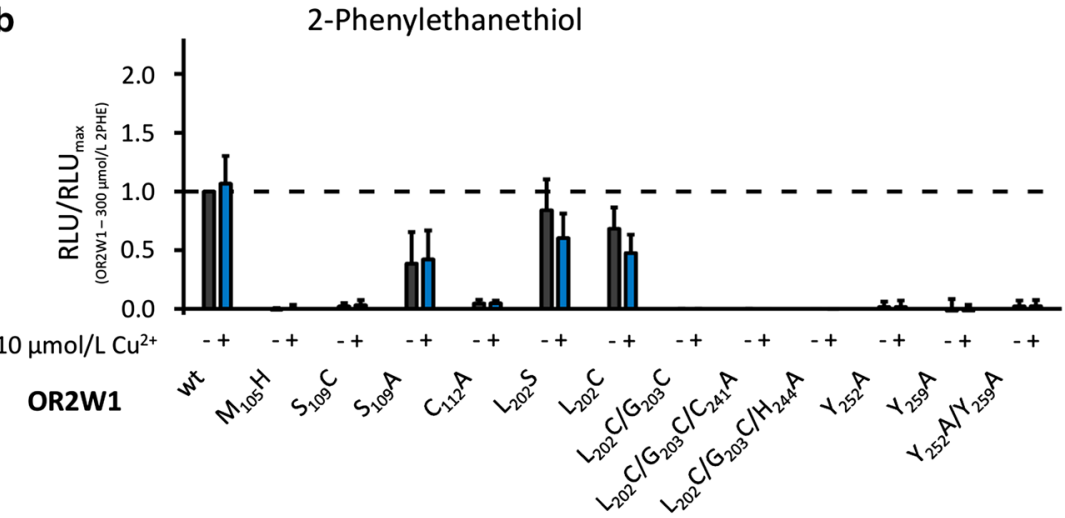

C

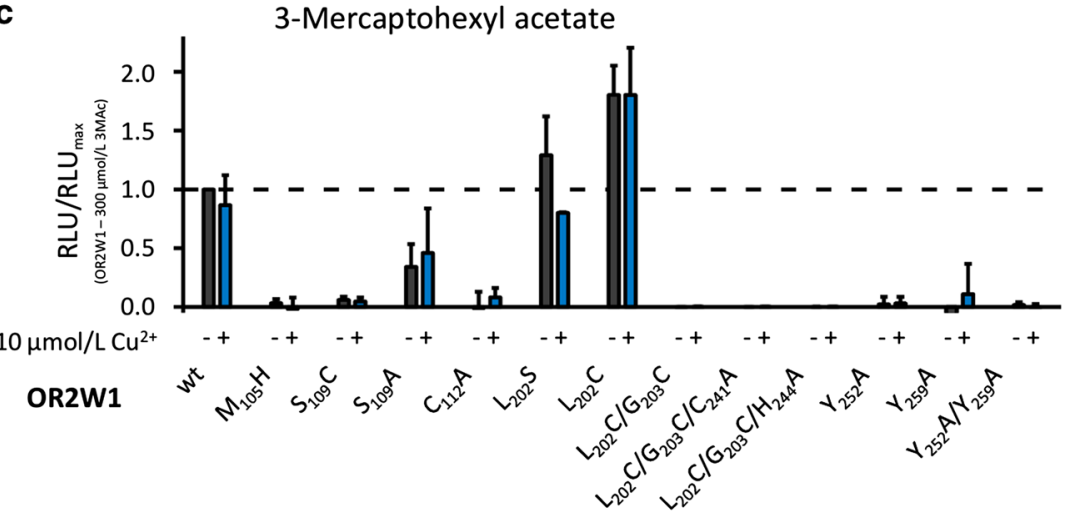

d Allyl phenyl acetate

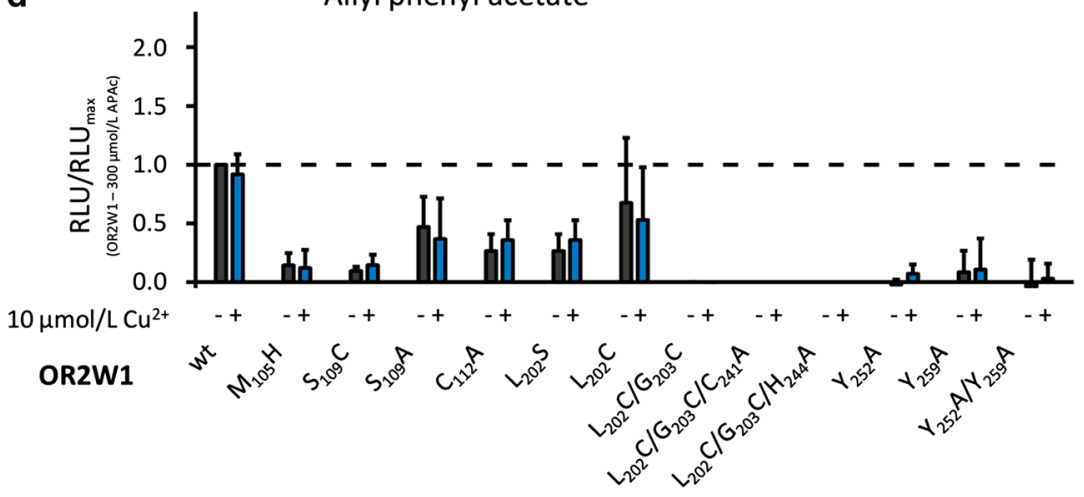


Table $3 E C_{50}$ values for OR2W1 with amino acid changes at positions of a putative copper/odorant-binding pocket measured in the absence and presence of $10 \mu \mathrm{mol} / \mathrm{L} \mathrm{Cu}^{2+}$

\begin{tabular}{|c|c|c|c|}
\hline Receptor & Agonist & $\begin{array}{l}\mathrm{EC}_{50} \text { in the absence of } \\
\mathrm{Cu}^{2+} \text { in } \mu \mathrm{mol} / \mathrm{L}^{\mathrm{a}}\end{array}$ & $\begin{array}{l}\mathrm{EC}_{50} \text { in the presence } \\
\text { of } \mathrm{Cu}^{2+} \text { in } \mu \mathrm{mol} / \mathrm{L}^{\mathrm{a}}\end{array}$ \\
\hline $\mathrm{OR} 2 \mathrm{~W} 1 \mathrm{~L}_{202} \mathrm{~S}$ & 2-Phenylethanethiol & $97.03 \pm 13.01$ & $96.73 \pm 4.66$ \\
\hline $\mathrm{OR} 2 \mathrm{~W} 1 \mathrm{~L}_{202} \mathrm{C}$ & 2-Phenylethanethiol & $65.08 \pm 10.80$ & $63.41 \pm 3.77$ \\
\hline $\mathrm{OR} 2 \mathrm{~W} 1 \mathrm{~S}_{109} \mathrm{~A}$ & 2-Phenylethanethiol & $34.41 \pm 9.98$ & $38.93 \pm 5.38$ \\
\hline $\mathrm{OR} 2 \mathrm{~W} 1 \mathrm{~L}_{202} \mathrm{~S}$ & 3-Mercaptohexyl acetate & $146.00 \pm 6.48$ & $310.73 \pm 22.11$ \\
\hline $\mathrm{OR} 2 \mathrm{~W} 1 \mathrm{~L}_{202} \mathrm{C}$ & 3-Mercaptohexyl acetate & $98.89 \pm 7.49$ & $114.43 \pm 10.46$ \\
\hline $\mathrm{OR} 2 \mathrm{~W} 1 \mathrm{~S}_{109} \mathrm{~A}$ & 3-Mercaptohexyl acetate & $146.49 \pm 23.01$ & $126.95 \pm 84.89$ \\
\hline $\mathrm{OR} 2 \mathrm{~W} 1 \mathrm{~L}_{202} \mathrm{~S}$ & Allyl phenyl acetate & $37.60 \pm 11.68$ & $46.00 \pm 14.34$ \\
\hline $\mathrm{OR} 2 \mathrm{~W} 1 \mathrm{~L}_{202} \mathrm{C}$ & Allyl phenyl acetate & $129.92 \pm 82.50$ & $73.00 \pm 42.12$ \\
\hline $\mathrm{OR} 2 \mathrm{~W} 1 \mathrm{~S}_{109} \mathrm{~A}$ & Allyl phenyl acetate & $46.04 \pm 11.63$ & $118.90 \pm 19.92$ \\
\hline
\end{tabular}

n.d. no detectable response up to $100 \mu \mathrm{mol} / \mathrm{L}$

${ }^{\mathrm{a}}$ Mean $\pm \mathrm{SD}(n=3-5)$ the absence of $\mathrm{Cu}^{2+}$. For the 'black currant'-like smelling 3-mercaptohexyl acetate, we observed increased amplitudes compared to OR2W1 wt for both OR2W $1 \mathrm{~L}_{202} \mathrm{~S}$ and OR2W1 $\mathrm{L}_{202} \mathrm{C}$ (Fig. S8e, h). The $E C_{50}$ values for OR2W1 $\mathrm{L}_{202} \mathrm{~S}$ were higher as compared to the wild type, with or without supplemental copper, but were lower for OR2W1 $\mathrm{L}_{202} \mathrm{C}$ (Table 3). The non-KFO allyl phenyl acetate revealed concentration-response relations for both OR2W1 Leu202 $2^{5.41}$ variants, with amplitudes reduced by half as compared to OR2W1 wt (Fig. S8f, i). Under both $\mathrm{Cu}^{2+}$ conditions, and compared to OR2W1 wt, the $E C_{50}$ values of allyl phenyl acetate for OR2W $1 \mathrm{~L}_{202} \mathrm{~S}$ were smaller, as observed also for 3-mercaptohexyl acetate, but, however, were higher for OR2W1 $\mathrm{L}_{202} \mathrm{C}$, as compared to 3-mercaptohexyl acetate (Table 3).

We further inserted the second cysteine at position $203^{5.42}$ in OR2W1, and tested OR2W1 $\mathrm{L}_{202} \mathrm{C} / \mathrm{G}_{203} \mathrm{C}$ with all three ligands. This variant, however, was not functional anymore (Fig. 6b-d).

Our results additionally identified amino acids Cys $241^{6.33}$ and His $244^{6.36}$ as being necessary for a potentiating effect of copper on 3-mercapto-2-methylpentan-1-ol function in OR2M3. Indeed, these positions previously have been reported to coordinate copper in OR2T11 [31]. We mutated the first and last positions of the CSSH motif in OR2W1, Cys $241^{6.33}$, and His $244^{6.36}$, by changing each amino acid to an alanine, and combined each with the double-mutation OR2W1 $\mathrm{L}_{202} \mathrm{C} / \mathrm{G}_{203} \mathrm{C}$. In our hands, both OR2W1 variants, OR2W1 L ${ }_{202} \mathrm{C} / \mathrm{G}_{203} \mathrm{C} / \mathrm{C}_{241} \mathrm{~A}$ and OR2W1 $\mathrm{L}_{202} \mathrm{C} / \mathrm{G}_{203} \mathrm{C} /$ $\mathrm{H}_{244} \mathrm{~A}$ were not functional anymore for all three tested compounds, in the absence or presence of $\mathrm{Cu}^{2+}$ (Fig. 6b-d).

For several odorant receptors, tyrosines at positions $252^{6.44}$ and $259^{6.51}$ have been shown to be involved in ligand binding [10, 32, 50, 94-99]. We, therefore, exchanged these tyrosines to alanines and tested the resulting OR2W1 variants against the three agonists 2-phenylethanethiol, 3-mercaptohexyl acetate, and allyl phenyl acetate. Both OR2W1
$\mathrm{Y}_{252} \mathrm{~A}$ and OR2W1 $\mathrm{Y}_{259} \mathrm{~A}$, as well as the double mutant OR2W1 $\mathrm{Y}_{252} \mathrm{~A} / \mathrm{Y}_{259} \mathrm{~A}$ were non-functional (Fig. 6b-d).

\section{Docking and molecular dynamic simulation of broadly tuned OR2W1 revealed a ligand-binding site about twice as big as in narrowly tuned OR2M3}

Figure 7a shows the homology model of OR2W1. Figure 7b shows the accessible volume of the ligand for OR2W1 which is $1138.07 \AA^{3}$, compared to $695.26 \AA^{3}$ for OR2M3 (see Fig. 5b). We performed molecular dynamic simulation to see the dynamic stability of ligands in the binding site of OR2W1. The docking calculations show that the ligands, 3-mercaptohexyl acetate and allyl phenyl acetate, bind by forming an H-bond with Tyr259 $9^{6.51}$ in OR2W1 (Fig. 7c-h). The residue Tyr $259^{6.51}$ is on the top of the TM region and close to the extracellular loop. The 3-mercaptohexyl acetate (Fig. $7 \mathrm{~d}+\mathrm{g}$ ) and allyl phenyl acetate (Fig. $7 \mathrm{e}+\mathrm{h}$ ) show similar results. However, 2-phenylethanethiol does not show any H-bond with Tyr $259^{6.51}$, but rather $\pi-\pi$ stacking with Tyr252 $2^{6.44}$ (Fig. 7c + f). The binding site also consists of Met $105^{3.33}$, Ser109 $9^{3.37}$, and Cys112 $2^{3.40}$, however, we did not find any $\mathrm{H}$-bonding interactions with the ligand. Rather, these residues appear to be important for stabilizing the ligand-binding site (see Fig. 7c-e, H-bond between Met $105^{3.33}$ and Ser109 $9^{3.37}$ ).

It is known that dynamical binding modes determine agonistic and antagonistic ligand effects in GPCRs [100]. Our 62 ns stimulation of OR2W1 in a water box without a membrane revealed a stabilization to $\sim 4.5 \AA$ after the first $12 \mathrm{~ns}$ (Fig. S5), and for the ligand 3-mercaptohexyl acetate, a free-binding energy of $-22.67 \pm 2.02 \mathrm{kcal} / \mathrm{mol}$. In the last $50 \mathrm{~ns}$ of the simulation, the ligand hydrogen bonded with the Tyr $259^{6.51}$ side chain $64.33 \%$ of the time, the Val $199^{5.38}$ backbone $48.34 \%$, and Gly $203^{5.42}$ only $0.16 \%$. Thus, dynamic modeling confirmed Tyr $259^{6.51}$ as the major ligand-interaction site via an $\mathrm{H}$-bond as proposed by our static model. 

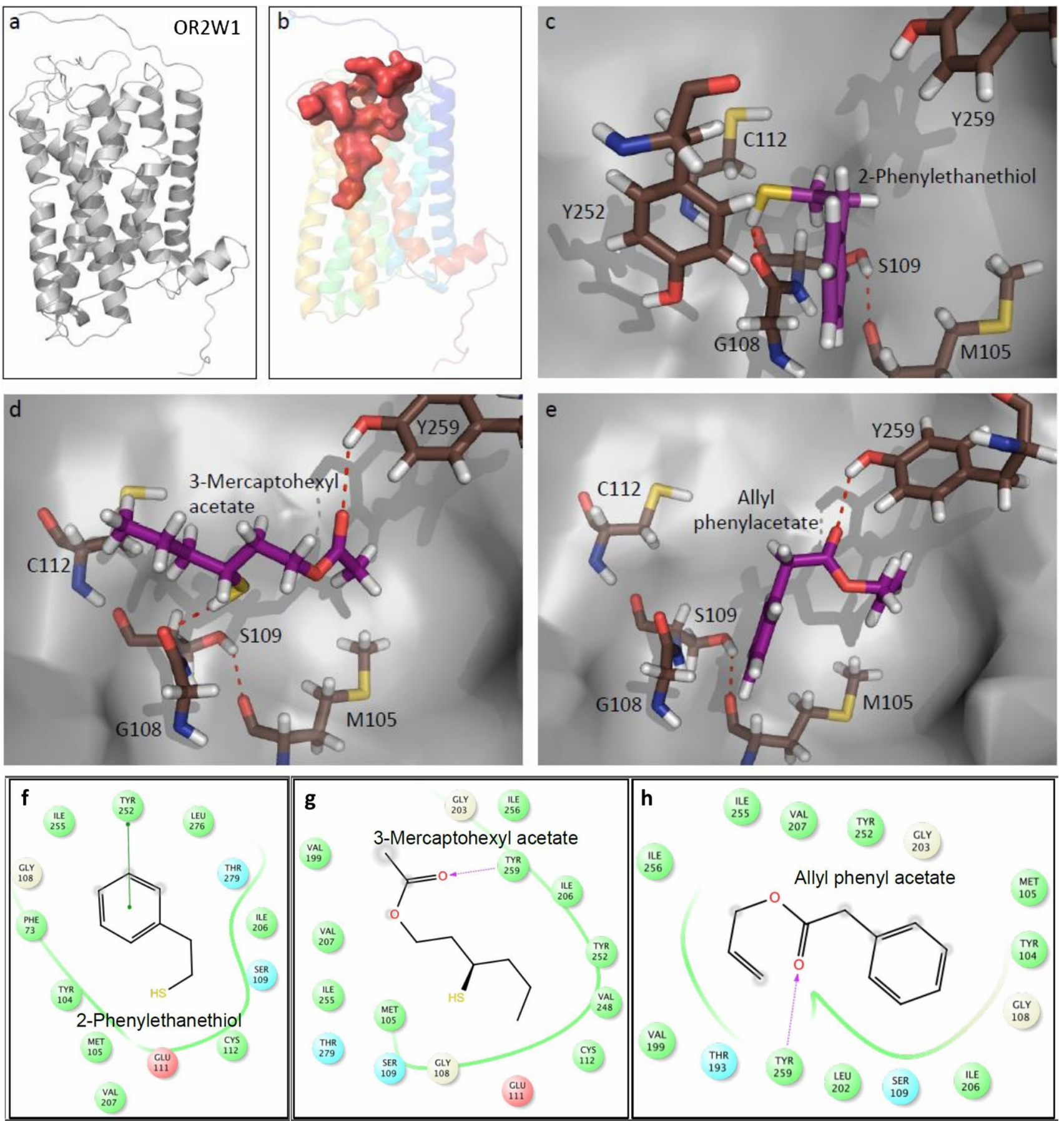

Fig. 7 Molecular modeling reveals no copper-binding site within OR2W1. a Homology model of OR2W1. b Accessible volume of the ligand in OR2W1. QM/MM structural models for OR2W1 show the docked ligands 2-phenylethanethiol c, 3-mercaptohexyl acetate (d), or allyl phenyl acetate (e). Residues defining the binding pocket are shown as sticks (oxygen: red; nitrogen: blue; sulfur: yellow).
Ligand-OR2W1 interactions for 2-phenylethanethiol (f), 3-mercaptohexyl acetate (g), or allyl phenyl acetate (h). Polar residues (blue), hydrophobic residues (green), negative charged residues (red), Glycine (beige), $\pi-\pi$ stacking (green line), and H-bonding interactions (dashed magenta line) 


\section{The putative copper-binding motif ' $\mathrm{CC} / \mathrm{CSSH}$ ' is conserved within phylogenetic clades that harbor the only known thiol-specific and copper-sensitive ORs}

The identified putative copper-binding motif in OR2M3, comprising site 1 (Cys $\left.202^{5.41} / \mathrm{Cys} 203^{5.42}\right)$ and site 2 (Cys241 ${ }^{6.33} / \mathrm{Ser} 242^{6.34} / \mathrm{Ser} 243^{6.35} / \mathrm{His} 244^{6.36}$ ), is $100 \%$ conserved among its closest homologs in 42 mammalian species (Fig. S11), and among 23 receptors within 3 subfamilies of family 2 human ORs, namely subfamilies M, T, and $\mathrm{V}$ (Fig. 8c). The closest 60 homologs of the 23 subfamily M/T/V ORs across 5 species (Table S5) show 100\% conservancy in the CC/CSSH motif, with one exception: the dog ortholog of OR2T11 has CC/CFSH (Fig. 8d). Indeed, subfamily $\mathrm{T}$ of family 2 ORs harbors the only other known thiol-specific receptor, OR2T11 - its activation by 2-methyl2-propanethiol depended on the presence of copper [31] (Fig. 8e, f). Position Thr105 $5^{3.33}$ (TMH 3), that supposedly forms one $\mathrm{H}$-bond with the ligand in OR2M3, is conserved in only $33 \%$ among 42 orthologs, but not at all conserved in paralogs of OR2M3 (Fig. S11). Cys202 $2^{5.41}$ (TMH 5), however, which forms the other $\mathrm{H}$-bond with the ligand, is conserved in $100 \%$ of all homologs (Fig. S11).

In contrast, broadly tuned OR2W1 does not depend on copper for responding to its thiol ligands, and lacks site 1 ('CC') of the putative copper-binding motif (see Fig. 2b, d, d, f). Here, both cysteines are replaced by Leu202 2.41 / Gly $203^{5.42}$, which lack a sulfhydryl group, and, therefore, are unlikely to interact with copper (Fig. S12). Moreover, site 2 ('CSSH') in OR2W1 lacks the first serine (Cys241 6.33/ Gly $242^{6.34} /$ Ser $243^{6.35} /$ His $244^{6.36}$ ).

\section{Discussion}

Thiols are important carriers of information-as key food odorants, determining the aroma of foods [6, 21], as body odors [18, 19], or as environmental odors [20]. The observation that thiols, compared to other volatiles, frequently display particularly low odor thresholds [23-25, 101], sprouted various theories trying to explain this behavior, with the aim to gain an understanding of odorant information coding at the receptor level. Common to all of these theories is the association of a thiol-receptor interaction with participation of transition metal ions such as copper, zinc, or nickel [27-31, 46, 47]. However, so far, only a single human cognate thiol odorant/receptor pair was identified (2-methyl2-propanethiol/OR2T11, [31]), which could be used to put these theories to the test.

In the present study, we now identified OR2M3 as a further copper-sensitive human receptor, which showed a three-to-sixfold potentiation of its specific ligand's efficacy by copper and silver ions (and colloidal silver), although this cognate receptor/ligand combination also functions in the absence of supplemented metal ions, as shown previously [6].

In an aqueous solution, $\mathrm{Cu}^{2+}$ is more stable than $\mathrm{Cu}^{+}$(in spite of $\mathrm{Cu}^{+}$having a filled d-subshell), because the solvation energy of $\mathrm{Cu}^{2+}$ is significantly larger than the solvation energy of $\mathrm{Cu}^{+}$and thus overcompensates the second ionization energy. For silver, however, the relative energies of the two oxidation states are switched, namely, $\mathrm{Ag}^{+}$is more stable than $\mathrm{Ag}^{2+}$. The reason for this is that the filled $4 \mathrm{~d}$ shell of $\mathrm{Ag}^{+}$is not sufficiently effective at shielding the nuclear charge making the second ionization energy so high that is not compensated by the solvation energy of $\mathrm{Ag}^{2+}$. $\mathrm{As}$ a result, silver is usually found as $\mathrm{Ag}^{+}$in aqueous environments, forming rather unstable complexes with very low coordination numbers (e.g., 2). However, the incomplete solvation of $\mathrm{Cu}^{2+}$ in the constrained cavity of the ligandbinding site of an OR might make $\mathrm{Cu}^{+}$the more stable form with a filled d-subshell. Therefore, it is natural to expect that silver could mimic copper as found by activation of OR2T11, which effect was also modeled computationally [31]. In addition, it is well known that both silver [102] and copper clusters bind thiolates [103], so they are expected to produce similar effects in the OR cavities that are sufficiently large as to bind metallic nanoparticles. In part, the significant effect of silver is due to the fact that, unlike copper, there is no background silver in the cell culture medium, so the effect of added silver appears to be larger. Because nanoparticulate silver is an environmental contaminant, our findings on the interaction of silver NP with ORs may be relevant to deleterious exposure of aquatic animals/fish/birds to environmental silver.

We recently identified OR2M3 as a highly specific, narrowly tuned receptor for the thiol KFO 3-mercapto-2-methylpentan-1-ol [6]. In contrast, for the other thiol-specific human receptor, OR2T11, its activation by 2-methyl2 -propanethiol has been previously identified to entirely depend on the presence of copper ions [31]. Li et al. [31] showed that OR2T11 responded to nine monothiols or $\alpha$-mercaptothioethers, although this receptor has not been characterized to be narrowly or broadly tuned with respect to its natural ligand spectrum [31]. Thiols, however, have been shown to also activate broadly tuned receptors, i.e., OR1A1 and OR2W1 [5]. Notably, in the present study, we did not observe any potentiating effect of copper on their thiol agonists 2-phenylethanethiol and 3-mercaptohexyl acetate. In the case of 2-phenylethanethiol activating OR1A1, the presence of copper ions rather decreased its efficacy, suggesting a negative allosteric action of copper on this cognate ligand/receptor combination. In contrast, copper ions markedly reduced the potency of the same odorant in activating OR2W1, here suggesting an orthosteric competitive action 
Fig. 8 A highly conserved putative copper-binding motif in the family 2 OR subfamilies $\mathrm{M}, \mathrm{T}$, and $\mathrm{V}$. Alignments of TMH 5 and TMH 6 of all human ORs (a), all human family 2 ORs (b), human family $2 /$ subfamilies M, T, and V ORs (c), and family $2 /$ subfamilies $\mathrm{M}, \mathrm{T}$, and $\mathrm{V}$ ORs including 99 orthologs (Tab. S5) from mouse, rat, cow, chimp, and $\operatorname{dog}(\mathbf{d})$. Shown are sequence logos, the consensus sequence, and the human OR2M3 sequence with the 3-mercapto-2-methylpentan1-ol-copper-binding pocket (red boxes). The consensus amino acid refers to the most frequent one, which is determined by letter height and stacking order. The letters of each stack are ordered from the most frequent to the least frequent. Amino acid conservation is measured in bits, and $100 \%$ conservation correlates with 4.32 bits [76]. Basic amino acids $(\mathrm{K}, \mathrm{R}, \mathrm{H})$ are blue, polar $(\mathrm{G}, \mathrm{S}, \mathrm{T}, \mathrm{Y}, \mathrm{C})$ are green, hydrophilic $(\mathrm{Q}, \mathrm{N})$ are purple, acidic $(\mathrm{D}, \mathrm{E})$ are red, and hydrophobic (A, V, L, I, P, W, M, F) are black. (e) Phylogenetic tree of all human ORs. Family 2 ORs are shaded in green. Clades marked in red carry both sites of the conserved motif. (f) Phylogenetic sub-tree of family 2 ORs. Clades marked in red carry both sites of the conserved $\mathrm{Cu}^{2+}$-binding motif

\section{Copper binding site 1} Human ORs

a

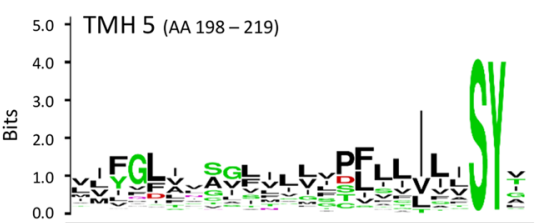

Consensus VIFGLIVVSGLILLVPFLLILISYV

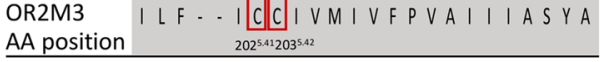

b

Family 2 ORs
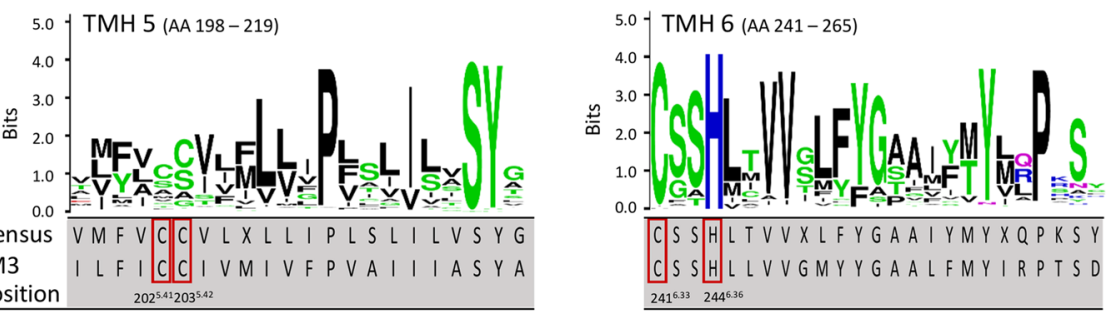

Human family 2 ORs subfamilies $M, T$ \& V

\section{Copper binding site 2}

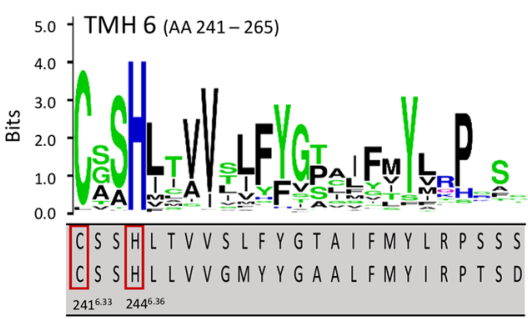

c

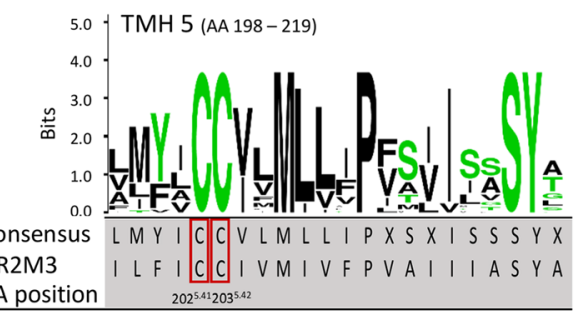

OR2M3 I L F I C C C I V V I VF PVA I I I A S Y A

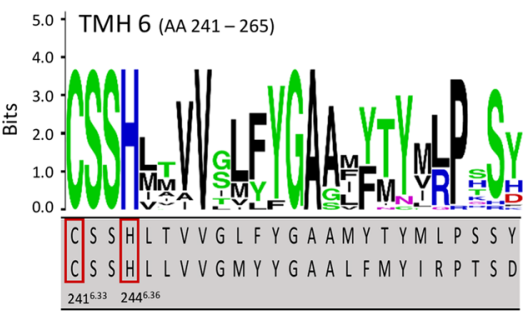

d

Family 2 ORs subfamilies M, T \& V including orthologs from mouse, rat, cow, chimp and dog

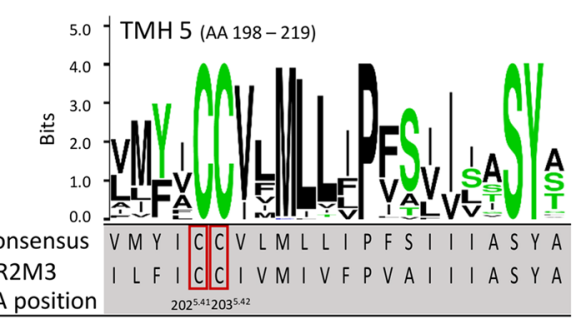
$202^{5 a 12} 203^{5 a 2}$

e

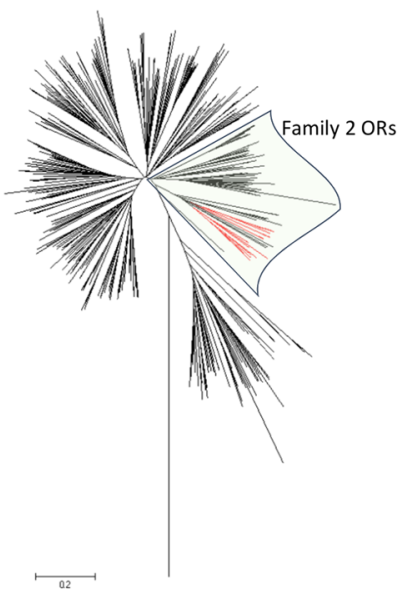

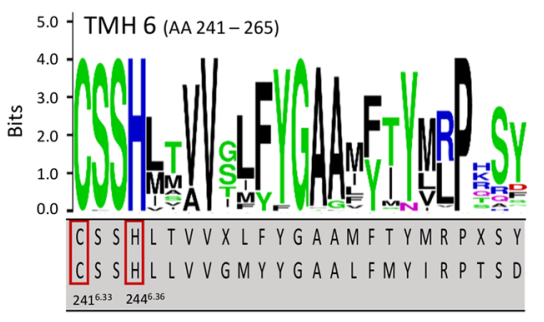

f

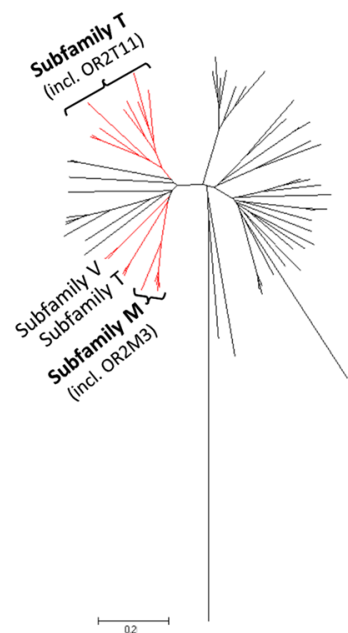


of copper ions on a 2-phenylethanethiol/receptor interaction. The lack of any enhancing effect of copper on the efficacy or affinity of a homologous series of $\mathrm{C}_{5}-\mathrm{C}_{8}$ aliphatic thiols on OR2W1 has recently been shown by Li et al. [31].

Our results support the notion that narrowly tuned receptors with a specificity for certain metal-coordinating thiols, e.g., OR2M3, have fewer degrees of freedom in accommodating multiple ligands in their binding pocket, which may be one causative factor that determines narrow tuning in these ORs. Indeed, our modeling study revealed that the accessible volume in OR2M3 for its ligand is smaller by a factor of 1.6 than the accessible volume in OR2W1 for its three investigated ligands. For non-metal-coordinating ORs, previous studies demonstrated receptor responses to depend on the molecular volume of an odorant, showing that affinity and/or efficacy became optimal when the molecular volume of an odorant matches the size of its binding pocket within the receptor [104, 105]. Baud et al. [50] reported on two mouse receptors, Olfr73 and Olfr74, to be broadly and narrowly tuned, respectively [50]. Broadly tuned Olfr73 in their hands, however, had the smaller calculated accessible volume compared to narrowly tuned Olfr74, which they attributed to smaller ligand sizes [50].

Our model of OR2M3 predicted two amino acid positions that may form H-bonds with the ligand 3-mercapto2-methylpentan-1-ol, Thr105 $5^{3.33}$, and Cys $202^{5.41}$. Of these, Thr $105^{3.33}$ has also ligand-binding function in human receptors OR1A1 (Ile105 $5^{3.33}$ ) [64], OR1G1 (Met105 ${ }^{3.33}$ ) [9], and OR3A1 (His108 ${ }^{3.33}$ ) [106], and in the mouse receptors
Olfr73 (MOR174-9; mOR-EG) and Olfr74 (MOR1444; mOR-EV) (Cys106 ${ }^{3.33}$ ) [50, 98] (Fig. S13, Table 4). A ligand-binding function of position Cys $202^{5.41}$ was previously reported for human OR1G1 (Ile201 ${ }^{5.41}$ ) and OR7D4 (Ala202 $2^{5.41}$ ) [97] and for mouse Olfr544 (MOR42-3) $\left(\right.$ Thr205 ${ }^{5.41}$ ) [107] (summarized in Fig. S13 and Table 4). Of these two ligand-interacting amino acid positions in OR2M3, Thr $105^{3.33}$ overlaps with a modeled, generalized odorant-binding pocket in ORs, proposed by Man et al. [88]. For OR2W1, our model suggested two amino acid positions to be involved in ligand binding (summarized in Fig. S13 and Table 5), one of which (Tyr252 ${ }^{6.44}$ ) overlaps with the 22 amino acid residues proposed by Man et al. [88]. Depending on the polarity of a ligand, the binding pocket in OR2W1 supports hydrophobic contacts with non-polar amino acid residues, which has been suggested as the dominant mode of interaction between ligands and broadly tuned ORs, favoring multiple binding modes through opportunistic interactions [9]. Our data may very well be interpreted in line with such a concept of multiple ligand-specific binding modes, which may induce different OR conformations and signaling responses, and thus may be the mechanistic basis for ORs to be broadly tuned $[9,50]$.

Beyond modeling the ligand-bound receptor, in silico docking of heavy metal ions into an OR model is a further challenge. The amino acid cysteine has a thiol function, and many cofactors in proteins and enzymes feature cysteinatemetal cofactors. A cysteine residue in ECL 2, Cys179, plays a major role in the tertiary structure of ORs by forming a

Table 4 Amino acids constituting an odorant and copper-binding site in OR2M3

\begin{tabular}{|c|c|c|c|c|c|c|}
\hline $\mathrm{TMH}_{\text {segment }}{ }^{\mathrm{a}}$ & $\begin{array}{l}\text { AA position } \\
\text { within TMH } \\
\text { segment }^{\mathrm{a}}\end{array}$ & $\begin{array}{l}\text { Mutagenesis-validated } \\
\text { 3-Mercapto-2-methyl- } \\
\text { pentan-1-ol binding site } \\
\text { positions }\end{array}$ & $\begin{array}{l}\text { 3-Mercapto- } \\
\text { 2-methyl-pen- } \\
\text { tan-1-ol }\end{array}$ & Copper & $\begin{array}{l}\text { 3-Mercapto-2-methyl- } \\
\text { pentan-1-ol and } \\
\text { copper }\end{array}$ & $\begin{array}{l}\text { Validated positions in other } \\
\text { ORs }\end{array}$ \\
\hline TMH 3 & 8 & ${ }^{\mathrm{b}, \mathrm{c}} \mathrm{Thr} 105^{3.33}$ & H-bond & Indirect & H-bond & 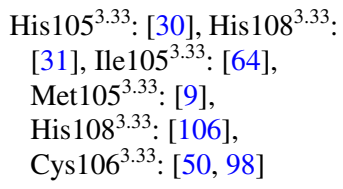 \\
\hline TMH 3 & 21 & Met118 3.46 & No interaction & Direct & Direct & Met115 $5^{3.46}:[31]$ \\
\hline TMH 5 & 5 & ${ }^{\mathrm{c}}$ Cys $202^{5.41}$ & H-bond & Direct & H-bond via copper & $\begin{array}{c}\text { Asn202 } 2^{5.41}:[30], \\
\text { Thr202 } \\
\text { Asn202. } 202^{5.41}:[9], \\
\text { Thr205], } \\
5.41:[95]\end{array}$ \\
\hline TMH 5 & 6 & ${ }^{\mathrm{b}}$ Cys $203^{5.42}$ & No interaction & Direct & H-bond via copper & $\begin{array}{l}\text { Thr203 }{ }^{5.42}:[97], \\
\text { Val206 } \\
\text { Phe207.42: } \\
\text { [107], }\end{array}$ \\
\hline TMH 6 & 1 & ${ }^{\mathrm{c} C y s} 241^{6.33}$ & Indirect & Direct & Direct & Cys $238^{6.33}:[31]$ \\
\hline TMH 6 & 4 & His $244^{6.36}$ & No interaction & Direct & Direct & His $241^{6.36}:[31]$ \\
\hline
\end{tabular}

${ }^{\mathrm{a}}$ HORDE [81]

${ }^{\mathrm{b}}$ Proposed amino acid positions constituting an odorant-binding site according to Man et al. [88]

c3-Mercapto-2-methylpentan-1-ol-binding site in OR2M3 
Table 5 Amino acids constituting an odorant and copper-binding site in OR2W1

\begin{tabular}{|c|c|c|c|c|c|c|}
\hline $\mathrm{TMH}_{\text {segment }} \mathrm{a}^{\mathrm{a}}$ & $\begin{array}{l}\text { AA position } \\
\text { within TMH } \\
\text { segment }^{\mathrm{a}}\end{array}$ & $\begin{array}{l}\text { Mutagenesis-vali- } \\
\text { dated binding site } \\
\text { positions }\end{array}$ & $\begin{array}{l}\text { 2-Phenyl- } \\
\text { ethanethiol }\end{array}$ & $\begin{array}{l}\text { 3-Mercaptohexyl } \\
\text { acetate }\end{array}$ & Allyl phenyl acetate & $\begin{array}{l}\text { Validated positions } \\
\text { in other ORs }\end{array}$ \\
\hline TMH 3 & 8 & ${ }^{\mathrm{b}} \operatorname{Met} 105^{3.33}$ & Indirect & Indirect & Indirect & 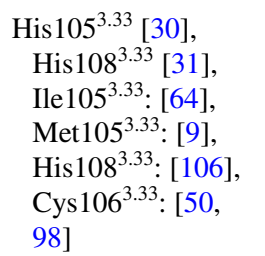 \\
\hline TMH 3 & 12 & ${ }^{\mathrm{b}} \operatorname{Ser} 109^{3.37}$ & Indirect & Indirect & Indirect & $\begin{array}{c}\text { Cys } 109^{3.37}:[30] \\
\text { Asn } 109^{3.37}:[10, \\
94], \text { Val113 } 3^{3.37}: \\
{[107,123]}\end{array}$ \\
\hline TMH 3 & 15 & ${ }^{\mathrm{b}}$ Cys $112^{3.40}$ & Indirect & Indirect & Indirect & $\begin{array}{l}\text { Ser112 } 2^{3.40}:[10], \\
\quad \text { Ser113 } \\
117], \text { Cys } 116^{3.40}: \\
{[123]}\end{array}$ \\
\hline TMH 6 & 12 & ${ }^{\mathrm{b}}$ Tyr252 6.44 & $\pi-\pi$ staking & No interaction & No interaction & $\begin{array}{c}\text { Tyr2516.44: }[10,94], \\
\operatorname{Tyr} 256^{6.44}:[95], \\
\text { Tyr252 } \\
6.44:[96]\end{array}$ \\
\hline TMH 6 & 19 & Tyr $259^{6.51}$ & No interaction & H-bond & H-bond & 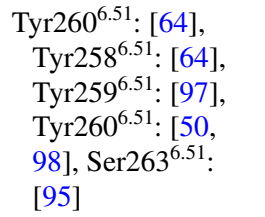 \\
\hline
\end{tabular}

${ }^{\mathrm{a}} \mathrm{HORDE}[81]$

${ }^{\mathrm{b}}$ Proposed amino acid positions constituting an odorant-binding site according to Man et al. [88]

disulfide bond with TMH 3 [86-88]. The same cysteine has been suggested to play a central role in the hypothesized metal-coordinating HxxC[DE] motif of ECL 2 [28]. In our hands, Cys179 mutants showed a complete loss-of-function, in the absence or presence of copper ions. Moreover, our docking-model did not suggest a direct interaction of Cys179 with the ligand or the copper ion, consonant with the idea of Cys179 rather being a structural requirement for ORs.

In the present study, our model of OR2M3, together with site-directed mutagenesis and functional testing of OR2M3 mutants, instead identified two positions, Cys $202^{5.41}$ and Cys $203^{5.42}$, constituting copper-coordinating binding site 1 ('CC'). Another two positions, Cys $241^{6.33}$ and His $244^{6.36}$, supposedly constitute copper-coordinating binding site 2 ('CSSH'). The latter one has been identified as a copper-coordinating site also in OR2T11 ('CSSHL') [31]. In the same study, another copper-coordinating site has been proposed in the cytoplasmic regions of TMH2 and TMH4 of OR2T11 [31]. In our study, the presence of two copper-binding sites in OR2M3 is corroborated by steeper concentration-response curves of its agonist 3-mercapto2-methylpentan-1-ol in the presence of copper, with a Hill coefficient of 1.9, suggesting their cooperativity [108]. The observation that copper concentration-dependently inhibited its potentiation of a 3-mercapto-2-methylpentan-1-oldependent activation of OR2M3 may be due to the ability of copper to coordinate the thiol, removing it and making it unavailable to activate the receptor. Copper-coordinating site 2 ('CSSH') in our model overlaps with the 'ionic lock' region at the cytoplasmic end of TMH6 of GPCRs, involved in $\mathrm{G}$ protein interaction (for review, see $[109,110]$ ). Also in ORs, this motif has been suggested as a zinc-binding motif, involved in G protein interaction [34]. GPCRs are allosterically modulated receptors $[111,112]$, often displaying constitutive activity $[113,114]$. For the first time, here, we show that copper concentration-dependently inhibited a constitutive activity of OR2M3 in the absence of ligand. This suggests that copper acts as an inverse agonist on OR2M3. To validate an inverse agonist action of copper on ORs, further studies, using the $\left[{ }^{35} \mathrm{~S}\right] \mathrm{GTP}$-gamma-S binding assay [115], may reveal the effect of copper on ORs' constitutive activation of their heterotrimeric $\mathrm{G}$ protein. Our results also support the notion of an allosteric, ligand-independent interaction of copper with site 2 ('CSSH') in this receptor. Our findings are in line with reports on copper and other transition metals as dynamic allosteric regulators of protein function at external allosteric sites [42]. 
Knowledge of the protein structure of a receptor is critical for an understanding of its ligand interactions. However, no high-resolution crystal structure of an OR has so far been reported. Given that ORs have only about $25 \%$ sequence identity with class A GPCRs, homology modeling of ORs may be of limited informative value. Nevertheless, the strategy of combining site-directed mutagenesis, functional experimental analysis, in silico homology modeling, and docking simulations has proven successful in uncovering mechanisms of odorant/ receptor interactions and OR structure-function relationships [10, 30, 31, 94, 96, 98, 107, 116-118]. A phylogenetic analysis will, therefore, add information on the relevance of conserved amino acid positions or motifs in ORs [96, 119-122].

In the present study, our phylogenetic analysis demonstrates that at least the cysteine and histidine of site 2 of the putative copper-binding motif (' $\mathrm{CxxH}$ ') are conserved in all ORs. The entire 'CSSH' motif, however, is highly conserved in human family 2 ORs, and $100 \%$ conserved only within subfamilies ' $\mathrm{M}, \mathrm{T}, \mathrm{V}$ ' of family 2 ORs, which harbor the closest human homologs of OR2M3 [6], and of OR2T11, the only other copper-sensitive human receptor reported, so far. In contrast, both cysteines of site 1 are not conserved over family 2 ORs or all human ORs. However, both sites together are $100 \%$ conserved only in human receptors of subfamilies ' $\mathrm{M}, \mathrm{T}, \mathrm{V}$ ' of family $2 \mathrm{ORs}$, but also in their orthologs from, e.g., chimp, mouse, or cow. Our phylogenetic and mutational analysis, and our homology modeling/ docking studies, altogether suggests that the entire motif ('CC'/'CSSH') is necessary for a potentiating effect of copper, and predicts members from at least these three subfamilies of human ORs to be narrowly tuned, thiol-specific, and copper-modulated receptors. Further experiments are needed to identify the ligands for at least all family 2 ORs, and to clarify whether a copper-sensitive, specific detection of thiol odorants is idiosyncratic to human subfamilies $\mathrm{M}, \mathrm{T}$, and $\mathrm{V}$ of family 2 ORs, and their orthologs.

Recently, however, an enhancing effect of copper on the odorant activation of mouse receptors Olfr 1509, Olfr1508, and Olfr1019 has been demonstrated [30-32], albeit these receptors lack site 1 (in our model: Cys202/Cys203 in TMH5, 'CC') and possess only a 'CxxH' site 2 . Here, other QM/MM- and site-directed mutagenesis-based copper-coordinating amino acids have been proposed. The corresponding human orthologs are from families 4 and 5 of ORs, suggesting that different copper-binding sites within ORs may have developed in different phylogenetic clades.

Here, we show that the specific thiol function of human OR2M3 is modulated by copper ions. Our homology modeling/docking studies together with receptor functional expression studies suggest that this copper sensitivity is mediated by two copper-binding sites within narrowly tuned OR2M3. This putative copper-binding motif is exclusively found in subfamilies $\mathrm{M}, \mathrm{T}$, and $\mathrm{V}$ of family 2 ORs, and appears to be conserved across their mammalian orthologs, suggesting a conserved copper-sensitive and specific thiol function of these receptors.

Acknowledgements This work was supported in part by NSF (CHE1265679) and NIH (5R01 DC014423-02 subaward) (E.B.). This work was supported by NIH grant GM106121 and supercomputer time from NERSC (V. S. B.). L.A. acknowledges National Science Foundation's XSEDE Startup grant (MCB160208) for supercomputer time. We thank Antonella Di Pizio for helpful discussions.

Open Access This article is distributed under the terms of the Creative Commons Attribution 4.0 International License (http://creativeco mmons.org/licenses/by/4.0/), which permits unrestricted use, distribution, and reproduction in any medium, provided you give appropriate credit to the original author(s) and the source, provide a link to the Creative Commons license, and indicate if changes were made.

\section{References}

1. Buck L, Axel R (1991) A novel multigene family may encode odorant receptors-a molecular-basis for odor recognition. Cell 65(1):175-187

2. Olender T, Lancet D, Nebert DW (2008) Update on the olfactory receptor (or) gene superfamily. Hum Genomics 3(1):87-97

3. Kato A, Touhara K (2009) Mammalian olfactory receptors: pharmacology, g protein coupling and desensitization. Cell Mol Life Sci 66(23):3743-3753

4. Verbeurgt C, Wilkin F, Tarabichi M, Gregoire F, Dumont JE, Chatelain P (2014) Profiling of olfactory receptor gene expression in whole human olfactory mucosa. PLoS One 9(5):e96333

5. Geithe C, Noe F, Kreissl J, Krautwurst D (2017) The broadly tuned odorant receptor or $1 \mathrm{a} 1$ is highly selective for 3-methyl2,4-nonanedione, a key food odorant in aged wines, tea, and other foods. Chem Senses 42(3):181-193

6. Noe F, Polster J, Geithe C, Kotthoff M, Schieberle P, Krautwurst D (2017) Or2m3: a highly specific and narrowly tuned human odorant receptor for the sensitive detection of onion key food odorant 3-mercapto-2-methylpentan-1-ol. Chem Senses 42(3):195-210

7. Malnic B, Hirono J, Sato T, Buck LB (1999) Combinatorial receptor codes for odors. Cell 96(5):713-723

8. Nara K, Saraiva LR, Ye X, Buck LB (2011) A large-scale analysis of odor coding in the olfactory epithelium. J Neurosci 31(25):9179-9191

9. Charlier L, Topin J, Ronin C, Kim SK, Goddard WA, 3rd, Efremov R, Golebiowski J (2012) How broadly tuned olfactory receptors equally recognize their agonists. Human or $1 \mathrm{~g} 1$ as a test case. Cell Mol Life Sci 69 (24):4205-4213

10. Schmiedeberg K, Shirokova E, Weber HP, Schilling B, Meyerhof W, Krautwurst D (2007) Structural determinants of odorant recognition by the human olfactory receptors or $1 \mathrm{a} 1$ and or $1 \mathrm{a} 2$. J Struct Biol 159(3):400-412

11. Saito H, Chi Q, Zhuang H, Matsunami H, Mainland JD (2009) Odor coding by a mammalian receptor repertoire. Sci Signal. 2 (60): ra9

12. Adipietro KA, Mainland JD, Matsunami H (2012) Functional evolution of mammalian odorant receptors. PLoS Genet 8(7):e1002821

13. Mainland JD, Li YR, Zhou T, Liu WL, Matsunami H (2015) Human olfactory receptor responses to odorants. Sci Data 2:150002

14. Sanz G, Schlegel C, Pernollet JC, Briand L (2005) Comparison of odorant specificity of two human olfactory receptors from different phylogenetic classes and evidence for antagonism. Chem Senses 30(1):69-80 
15. Hamada K, Haruyama S, Yamaguchi T, Yamamoto K, Hiromasa K, Yoshioka M, Nishio D, Nakamura M (2014) What determines human body odour? Exp Dermatol 23(5):316-317

16. Natsch A (2015) What makes us smell: the biochemistry of body odour and the design of new deodorant ingredients. Chimia (Aarau) 69(7-8):414-420

17. Starkenmann C, Niclass Y, Troccaz M, Clark AJ (2005) Identification of the precursor of $(s)$-3-methyl-3-sulfanylhexan-1-ol, the sulfury malodour of human axilla sweat. Chem Biodivers 2(6):705-716

18. Troccaz M, Starkenmann C, Niclass Y, van de Waal M, Clark AJ (2004) 3-methyl-3-sulfanylhexan-1-ol as a major descriptor for the human axilla-sweat odour profile. Chem Biodivers 1(7):1022-1035

19. Natsch A, Schmid J, Flachsmann F (2004) Identification of odoriferous sulfanylalkanols in human axilla secretions and their formation through cleavage of cysteine precursors by a c-s lyase isolated from axilla bacteria. Chem Biodivers 1(7):1058-1072

20. Rogers KL, Schulte MD (2012) Organic sulfur metabolisms in hydrothermal environments. Geobiology 10(4):320-332

21. Dunkel A, Steinhaus M, Kotthoff M, Nowak B, Krautwurst D, Schieberle P, Hofmann T (2014) Nature's chemical signatures in human olfaction: a foodborne perspective for future biotechnology. Angew Chem Int Ed Engl 53(28):7124-7143

22. Granvogl M, Christlbauer M, Schieberle P (2004) Quantitation of the intense aroma compound 3-mercapto-2-methylpentan-1-ol in raw and processed onions (allium cepa) of different origins and in other allium varieties using a stable isotope dilution assay. $\mathbf{J}$ Agric Food Chem 52(10):2797-2802

23. Li JX, Schieberle P, Steinhaus M (2012) Characterization of the major odor-active compounds in thai durian (durio zibethinus 1. 'Monthong') by aroma extract dilution analysis and headspace gas chromatography-olfactometry. J Agric Food Chem 60(45):11253-11262

24. Schoenauer S, Schieberle P (2016) Structure-odor activity studies on monoterpenoid mercaptans synthesized by changing the structural motifs of the key food odorant 1-p-menthene-8-thiol. J Agric Food Chem 64(19):3849-3861

25. Polster J, Schieberle P (2015) Structure-odor correlations in homologous series of alkanethiols and attempts to predict odor thresholds by 3d-qsar studies. J Agric Food Chem 63(5):1419-1432

26. Laska M, Bautista RM, Hofelmann D, Sterlemann V, Salazar LT (2007) Olfactory sensitivity for putrefaction-associated thiols and indols in three species of non-human primate. J Exp Biol 210(Pt 23):4169-4178

27. Crabtree RH (1978) Copper (i): a possible olfactory binding site. J Inorg Nucl Chem 40(7):1453

28. Wang J, Luthey-Schulten ZA, Suslick KS (2003) Is the olfactory receptor a metalloprotein? Proc Natl Acad Sci USA 100(6):3035-3039

29. Duan X, Block E, Li Z, Connelly T, Zhang J, Huang Z, Su X, Pan Y, Wu L, Chi Q, Thomas S, Zhang S, Ma M, Matsunami H, Chen GQ, Zhuang H (2012) Crucial role of copper in detection of metal-coordinating odorants. Proc Natl Acad Sci USA 109(9):3492-3497

30. Sekharan S, Ertem MZ, Zhuang H, Block E, Matsunami H, Zhang R, Wei JN, Pan Y, Batista VS (2014) Qm/mm model of the mouse olfactory receptor mor244-3 validated by site-directed mutagenesis experiments. Biophys J 107(5):L5-L8

31. Li S, Ahmed L, Zhang R, Pan Y, Matsunami H, Burger JL, Block E, Batista VS, Zhuang H (2016) Smelling sulfur: copper and silver regulate the response of human odorant receptor or $2 \mathrm{t} 11$ to low-molecular-weight thiols. J Am Chem Soc 138(40):13281-13288
32. Zhang R, Pan Y, Ahmed L, Block E, Zhang Y, Batista VS, Zhuang H (2018) A multispecific investigation of the metal effect in mammalian odorant receptors for sulfur-containing compounds. Chem Senses 43(5):357-366

33. Day JC (1978) New nitrogen bases with severe steric hindrance due to flanking tert-butyl groups - cis-2,6-di-tert-butylpiperidine-possible steric blocking of olfaction. J Org Chem 43(19):3646-3649

34. Turin L (1996) A spectroscopic mechanism for primary olfactory reception. Chem Senses 21(6):773-791

35. Block E (2018) Molecular basis of mammalian odor discrimination: a status report. J Agric Food Chem 66(51):13346-13366

36. Block E, Batista VS, Matsunami H, Zhuang H, Ahmed L (2017) The role of metals in mammalian olfaction of low molecular weight organosulfur compounds. Nat Prod Rep 34(5):529-557

37. Kinouchi K, Standifer KM, Pasternak GW (1990) Modulation of $\mu 1, \mu 2$, and $\delta$ opioid binding by divalent cations. Biochem Pharmacol 40(2):382-384

38. Gerlach LO, Jakobsen JS, Jensen KP, Rosenkilde MR, Skerlj RT, Ryde U, Bridger GJ, Schwartz TW (2003) Metal ion enhanced binding of amd 3100 to asp262 in the cxcr4 receptor. Biochemistry 42(3):710-717

39. Holst B, Elling CE, Schwartz TW (2002) Metal ion-mediated agonism and agonist enhancement in melanocortin $\mathrm{mc} 1$ and $\mathrm{mc} 4$ receptors. J Biol Chem 277(49):47662-47670

40. Chang CJ (2017) Bioinorganic life and neural activity: toward a chemistry of consciousness? Acc Chem Res 50(3):535-538

41. Que EL, Domaille DW, Chang CJ (2008) Metals in neurobiology: probing their chemistry and biology with molecular imaging. Chem Rev 108(5):1517-1549

42. Aron AT, Ramos-Torres KM, Cotruvo JA Jr, Chang CJ (2015) Recognition- and reactivity-based fluorescent probes for studying transition metal signaling in living systems. Acc Chem Res 48(8):2434-2442

43. Yokoi K, Uthus EO, Penland JG, Nielsen FH (2014) Effect of dietary nickel deprivation on vision, olfaction, and taste in rats. J Trace Elem Med Biol 28(4):436-440

44. Gordon SE, Zagotta WN (1995) Subunit interactions in coordination of $\mathrm{ni}^{2+}$ in cyclic nucleotide-gated channels. Proc Natl Acad Sci USA 92(22):10222-10226

45. Gordon SE, Zagotta WN (1995) Localization of regions affecting an allosteric transition in cyclic nucleotide-activated channels. Neuron 14(4):857-864

46. Viswaprakash N, Dennis JC, Globa L, Pustovyy O, Josephson EM, Kanju P, Morrison EE, Vodyanoy VJ (2009) Enhancement of odorant-induced responses in olfactory receptor neurons by zinc nanoparticles. Chem Senses 34(7):547-557

47. Vodyanoy V (2010) Zinc nanoparticles interact with olfactory receptor neurons. Biometals 23(6):1097-1103

48. Moore CH, Pustovyy O, Dennis JC, Moore T, Morrison EE, Vodyanoy VJ (2012) Olfactory responses to explosives associated odorants are enhanced by zinc nanoparticles. Talanta 88:730-733

49. Kotthoff M, Schieberle P, Krautwurst D (2010) Human olfactory receptors for thiol key food odorants. In: Wartburg symposium on flavor chemistry and biology. Eisenach, Chair for Food Chemistry, $9^{\text {th }}$ edn. Technische Universitaet Muenchen, Berlin

50. Baud O, Yuan S, Veya L, Filipek S, Vogel H, Pick H (2015) Exchanging ligand-binding specificity between a pair of mouse olfactory receptor paralogs reveals odorant recognition principles. Scientific Reports 5:14948

51. Block E (2010) Garlic and other alliums: the lore and the science. R Soc Chem. Cambridge, U.K

52. Geithe C, Andersen G, Malki A, Krautwurst D (2015) A butter aroma recombinate activates human class-i odorant receptors. J Agric Food Chem 63(43):9410-9420 
53. Krautwurst D, Yau KW, Reed RR (1998) Identification of ligands for olfactory receptors by functional expression of a receptor library. Cell 95(7):917-926

54. Shirokova E, Schmiedeberg K, Bedner P, Niessen H, Willecke K, Raguse JD, Meyerhof W, Krautwurst D (2005) Identification of specific ligands for orphan olfactory receptors. G proteindependent agonism and antagonism of odorants. J Biol Chem. 280(12):11807-11815

55. Hamprecht B, Glaser T, Reiser G, Bayer E, Propst F (1985) Culture and characteristics of hormone-responsive neuroblastoma $\mathrm{x}$ glioma hybrid cells. Methods Enzymol 109:316-341

56. Graham FL, Smiley J, Russell WC, Nairn R (1977) Characteristics of a human cell line transformed by DNA from human adenovirus type 5. J Gen Virol 36(1):59-74

57. Saito H, Kubota M, Roberts RW, Chi Q, Matsunami H (2004) Rtp family members induce functional expression of mammalian odorant receptors. Cell 119(5):679-691

58. Jones DT, Reed RR (1989) Golf: an olfactory neuron specific$\mathrm{g}$ protein involved in odorant signal transduction. Science 244(4906):790-795

59. Li F, Ponissery-Saidu S, Yee KK, Wang H, Chen ML, Iguchi N, Zhang G, Jiang P, Reisert J, Huang L (2013) Heterotrimeric g protein subunit ggamma13 is critical to olfaction. J Neurosci 33(18):7975-7984

60. Binkowski B, Fan F, Wood K (2009) Engineered luciferases for molecular sensing in living cells. Curr Opin Biotechnol 20(1):14-18

61. DeLean A, Munson PJ, Rodbard D (1978) Simultaneous analysis of families of sigmoidal curves: application to bioassay, radioligand assay, and physiological dose-response curves. Am J Physiol 235(2):E97-102

62. Sali A (1995) Comparative protein modeling by satisfaction of spatial restraints. Mol Med Today 1(6):270-277

63. Thal DM, Sun B, Feng D, Nawaratne V, Leach K, Felder CC, Bures MG, Evans DA, Weis WI, Bachhawat P, Kobilka TS, Sexton PM, Kobilka BK, Christopoulos A (2016) Crystal structures of the $\mathrm{m} 1$ and $\mathrm{m} 4$ muscarinic acetylcholine receptors. Nature 531(7594):335-340

64. Ahmed L, Zhang Y, Block E, Buehl M, Corr MJ, Cormanich RA, Gundala S, Matsunami H, O'Hagan D, Ozbil M, Pan Y, Sekharan S, Ten N, Wang M, Yang M, Zhang Q, Zhang R, Batista VS, Zhuang H (2018) Molecular mechanism of activation of human musk receptors or5an 1 and or1a1 by $(r)$-muscone and diverse other musk-smelling compounds. Proc Natl Acad Sci USA 115(17):E3950-E3958

65. Sondergaard CR, Olsson MH, Rostkowski M, Jensen JH (2011) Improved treatment of ligands and coupling effects in empirical calculation and rationalization of pka values. J Chem Theory Comput 7(7):2284-2295

66. Olsson MH, Sondergaard CR, Rostkowski M, Jensen JH (2011) Propka3: consistent treatment of internal and surface residues in empirical pka predictions. J Chem Theory Comput 7(2):525-537

67. Banks JL, Beard HS, Cao Y, Cho AE, Damm W, Farid R, Felts AK, Halgren TA, Mainz DT, Maple JR, Murphy R, Philipp DM, Repasky MP, Zhang LY, Berne BJ, Friesner RA, Gallicchio E, Levy RM (2005) Integrated modeling program, applied chemical theory (impact). J Comput Chem 26(16):1752-1780

68. Friesner RA, Murphy RB, Repasky MP, Frye LL, Greenwood JR, Halgren TA, Sanschagrin PC, Mainz DT (2006) Extra precision glide: docking and scoring incorporating a model of hydrophobic enclosure for protein-ligand complexes. J Med Chem 49(21):6177-6196

69. Friesner RA, Banks JL, Murphy RB, Halgren TA, Klicic JJ, Mainz DT, Repasky MP, Knoll EH, Shelley M, Perry JK, Shaw DE, Francis P, Shenkin PS (2004) Glide: a new approach for rapid, accurate docking and scoring. 1. Method and assessment of docking accuracy. J Med Chem 47(7):1739-1749

70. Halgren TA, Murphy RB, Friesner RA, Beard HS, Frye LL, Pollard WT, Banks JL (2004) Glide: a new approach for rapid, accurate docking and scoring. 2. Enrichment factors in database screening. J Med Chem 47(7):1750-1759

71. Phillips JC, Braun R, Wang W, Gumbart J, Tajkhorshid E, Villa E, Chipot C, Skeel RD, Kale L, Schulten K (2005) Scalable molecular dynamics with namd. J Comput Chem 26(16):1781-1802

72. Vreven T, Morokuma K, Farkas O, Schlegel HB, Frisch MJ (2003) Geometry optimization with $\mathrm{qm} / \mathrm{mm}$, oniom, and other combined methods. I. Microiterations and constraints. J Comput Chem 24(6):760-769

73. Frisch MJ, Trucks GW, Schlegel HB, Scuseria GE, Robb MA, Cheeseman JR, Scalmani G, Barone V, Petersson GA, Nakatsuji H, Li X, Caricato M, Marenich A, Bloino J, Janesko BG, Gomperts R, Mennucci B, Hratchian HP, Ortiz JV, Izmaylov AF, Sonnenberg JL, Williams-Young D, Ding F, Lipparini F, Egidi F, Goings J, Peng B, Petrone A, Henderson T, Ranasinghe D, Zakrzewski VG, Gao J, Rega N, Zheng G, Liang W, Hada M, Ehara M, Toyota K, Fukuda R, Hasegawa J, Ishida M, Nakajima T, Honda Y, Kitao O, Nakai H, Vreven T, Throssell K, Montgomery JA Jr, Peralta JE, Ogliaro F, Bearpark M, Heyd JJ, Brothers E, Kudin KN, Staroverov VN, Keith T, Kobayashi R, Normand J, Raghavachari K, Rendell A, Burant JC, Iyengar SS, Tomasi J, Cossi M, Millam JM, Klene M, Adamo C, Cammi R, Ochterski JW, Martin RL, Morokuma K, Farkas O, Foresman JB, Fox DJ (2009) Gaussian 09. Gaussian Inc, Wallingford CT

74. Zhao Y, Truhlar DG (2006) A new local density functional for main-group thermochemistry, transition metal bonding, thermochemical kinetics, and noncovalent interactions. J Chem Phys 125(19): 194101

75. Zhao Y, Truhlar DG (2008) The m06 suite of density functionals for main group thermochemistry, thermochemical kinetics, noncovalent interactions, excited states, and transition elements: two new functionals and systematic testing of four m06-class functionals and 12 other functionals. Theor Chem Acc 120:215-241

76. Wiberg KB (1986) Ab initio molecular orbital theory by W. J. Hehre, 1. Radom, P. V. R. Schleyer, J. A. Pople, John wiley, New York, 548 pp. J Comput Chem 7:379

77. Andrae D, Häußermann U, Dolg M, Preuß H, (1990) Energyadjusted ab initio pseudopotentials for the second and third row transition elements. Theor Chim Acta 77:123-141

78. Cornell WD, Cieplak P, Bayly CI, Gould IR, Merz KM, Ferguson DM, Spellmeyer DC, Fox T, Caldwell JW, Kollman PA (1995) A second generation force field for the simulation of proteins, nucleic acids, and organic molecules. J Am Chem Soc 117(19):5179-5197

79. Crooks GE, Hon G, Chandonia JM, Brenner SE (2004) Weblogo: a sequence logo generator. Genome Res 14(6):1188-1190

80. Schneider TD, Stephens RM (1990) Sequence logos: a new way to display consensus sequences. Nucleic Acids Res 18(20):6097-6100

81. Safran M, Chalifa-Caspi V, Shmueli O, Olender T, Lapidot M, Rosen N, Shmoish M, Peter Y, Glusman G, Feldmesser E, Adato A, Peter I, Khen M, Atarot T, Groner Y, Lancet D (2003) Human gene-centric databases at the Weizmann Institute of Science: genecards, udb, crow 21 and horde. Nucleic Acids Res 31(1):142-146

82. Saitou N, Nei M (1987) The neighbor-joining method: a new method for reconstructing phylogenetic trees. Mol Biol Evol 4(4):406-425

83. Zuckerkandl E, Pauling L (1965) Evolutionary divergence and convergence in proteins. In: Bryson V, Vogel HJ (eds) Evolving genes and proteins. Academic Press, Cambridge, pp 97-166 
84. Kumar S, Stecher G, Tamura K (2016) Mega7: molecular evolutionary genetics analysis version 7. 0 for bigger datasets. Mol Biol Evol 33(7):1870-1874

85. Sherry ST, Ward MH, Kholodov M, Baker J, Phan L, Smigielski EM, Sirotkin K (2001) Dbsnp: the ncbi database of genetic variation. Nucleic Acids Res 29(1):308-311

86. Cook BL, Steuerwald D, Kaiser L, Graveland-Bikker J, Vanberghem M, Berke AP, Herlihy K, Pick H, Vogel H, Zhang S (2009) Large-scale production and study of a synthetic g proteincoupled receptor: human olfactory receptor 17-4. Proc Natl Acad Sci USA 106(29):11925-11930

87. Liu AH, Zhang X, Stolovitzky GA, Califano A, Firestein SJ (2003) Motif-based construction of a functional map for mammalian olfactory receptors. Genomics 81(5):443-456

88. Man O, Gilad Y, Lancet D (2004) Prediction of the odorant binding site of olfactory receptor proteins by human-mouse comparisons. Protein Sci 13(1):240-254

89. Genomes Project C, Abecasis GR, Altshuler D, Auton A, Brooks LD, Durbin RM, Gibbs RA, Hurles ME, McVean GA (2010) A map of human genome variation from population-scale sequencing. Nature 467(7319):1061-1073

90. Bradley JM, Le Brun NE, Moore GR (2016) Ferritins: furnishing proteins with iron. J Biol Inorg Chem 21(1):13-28

91. Inesi $\mathrm{G}$ (2017) Molecular features of copper binding proteins involved in copper homeostasis. IUBMB Life 69(4):211-217

92. Peralta FA, Huidobro-Toro JP (2016) Zinc as allosteric ion channel modulator: ionotropic receptors as metalloproteins. Int J Mol Sci 17(7):1059

93. Quist DA, Diaz DE, Liu JJ, Karlin KD (2017) Activation of dioxygen by copper metalloproteins and insights from model complexes. J Biol Inorg Chem 22(2-3):253-288

94. Geithe C, Protze J, Kreuchwig F, Krause G, Krautwurst D (2017) Structural determinants of a conserved enantiomer-selective carvone binding pocket in the human odorant receptor or $1 \mathrm{a} 1$. Cell Mol Life Sci 74(22):4209-4229

95. Lai PC, Guida B, Shi J, Crasto CJ (2014) Preferential binding of an odor within olfactory receptors: a precursor to receptor activation. Chem Senses 39(2):107-123

96. de March CA, Yu Y, Ni MJ, Adipietro KA, Matsunami H, Ma M, Golebiowski J (2015) Conserved residues control activation of mammalian g protein-coupled odorant receptors. J Am Chem Soc 137(26):8611-8616

97. de March CA, Topin J, Bruguera E, Novikov G, Ikegami K, Matsunami H, Golebiowski J (2018) Odorant receptor 7d4 activation dynamics. Angew Chem Int Ed Engl 57(17):4554-4558

98. Baud O, Etter S, Spreafico M, Bordoli L, Schwede T, Vogel H, Pick H (2011) The mouse eugenol odorant receptor: structural and functional plasticity of a broadly tuned odorant binding pocket. Biochemistry 50(5):843-853

99. Kurland MD, Newcomer MB, Peterlin Z, Ryan K, Firestein S, Batista VS (2010) Discrimination of saturated aldehydes by the rat i7 olfactory receptor. Biochemistry 49(30):6302-6304

100. Wolf S, Jovancevic N, Gelis L, Pietsch S, Hatt H, Gerwert K (2017) Dynamical binding modes determine agonistic and antagonistic ligand effects in the prostate-specific g-protein coupled receptor (psgr). Scientific Reports 7(1):16007

101. Lai PC, Crasto CJ (2012) Beyond modeling: all-atom olfactory receptor model simulations. Front Genet 3:61

102. Jin R, Zhao S, Xing Y, Jin R (2016) All-thiolate-protected silver and silver-rich alloy nanoclusters with atomic precision: stable sizes, structural characterization and optical properties. Cryst Eng Comm 18(22):3996-4005

103. Konopka M, Rousseau R, Stich I, Marx D (2004) Detaching thiolates from copper and gold clusters: which bonds to break? J Am Chem Soc 126(38):12103-12111
104. Saberi M, Seyed-Allaei H (2016) Odorant receptors of drosophila are sensitive to the molecular volume of odorants. Sci Rep 6:25103

105. Zhang L, Yuan Y, Ren T, Guo Y, Li C, Pu X (2018) Shining light on molecular mechanism for odor-selectivity of cnt-immobilized olfactory receptor. Sci Rep 8(1):7824

106. Anselmi C, Buonocore A, Centini M, Facino RM, Hatt H (2011) The human olfactory receptor 17-40: requisites for fitting into the binding pocket. Comput Biol Chem 35(3):159-168

107. Abaffy T, Malhotra A, Luetje CW (2007) The molecular basis for ligand specificity in a mouse olfactory receptor: a network of functionally important residues. J Biol Chem 282(2):1216-1224

108. Lolkema JS, Slotboom DJ (2015) The hill analysis and co-iondriven transporter kinetics. J Gen Physiol 145(6):565-574

109. Ballesteros JA, Jensen AD, Liapakis G, Rasmussen SG, Shi L, Gether U, Javitch JA (2001) Activation of the beta 2-adrenergic receptor involves disruption of an ionic lock between the cytoplasmic ends of transmembrane segments 3 and 6. J Biol Chem 276(31):29171-29177

110. Deupi X, Standfuss J (2011) Structural insights into agonistinduced activation of g-protein-coupled receptors. Curr Opin Struct Biol 21(4):541-551

111. Sharma K, Balfanz S, Baumann A, Korsching S (2018) Full rescue of an inactive olfactory receptor mutant by elimination of an allosteric ligand-gating site. Sci Rep 8(1):9631

112. Milligan G, Smith NJ (2007) Allosteric modulation of heterodimeric g-protein-coupled receptors. Trends Pharmacol Sci 28(12):615-620 Epub 2007 Nov 2019

113. Reisert J (2010) Origin of basal activity in mammalian olfactory receptor neurons. J Gen Physiol 136(5):529-540

114. Seifert R, Wenzel-Seifert K (2002) Constitutive activity of g-protein-coupled receptors: cause of disease and common property of wild-type receptors. Naunyn Schmiedebergs Arch Pharmacol 366(5):381-416

115. Milligan G (2003) Principles: extending the utility of $35 \mathrm{~s}$ gtp gamma s binding assays. Trends Pharmacol Sci 24(2):87-90

116. de March CA, Kim SK, Antonczak S, Goddard WA 3rd, Golebiowski J (2015) G protein-coupled odorant receptors: from sequence to structure. Protein Sci 24(9):1543-1548

117. Katada S, Hirokawa T, Oka Y, Suwa M, Touhara K (2005) Structural basis for a broad but selective ligand spectrum of a mouse olfactory receptor: mapping the odorant-binding site. J Neurosci 25(7):1806-1815

118. Gelis L, Wolf S, Hatt H, Neuhaus EM, Gerwert K (2012) Prediction of a ligand-binding niche within a human olfactory receptor by combining site-directed mutagenesis with dynamic homology modeling. Angew Chem Int Ed Engl 51(5):1274-1278

119. Gottlieb A, Olender T, Lancet D, Horn D (2009) Common peptides shed light on evolution of olfactory receptors. BMC Evol Biol 9:91

120. Skoufos E (1999) Conserved sequence motifs of olfactory receptor-like proteins may participate in upstream and downstream signal transduction. Recept Channels 6(5):401-413

121. Menashe I, Aloni R, Lancet D (2006) A probabilistic classifier for olfactory receptor pseudogenes. BMC Bioinformatics 7:393

122. Felsenstein J (1985) Phylogenies and the comparative method. Am Nat 125(1):1-15

123. Bavan S, Sherman B, Luetje CW, Abaffy T (2014) Discovery of novel ligands for mouse olfactory receptor mor42-3 using an in silico screening approach and in vitro validation. PLOS ONE 9(3):e92064

Publisher's Note Springer Nature remains neutral with regard to jurisdictional claims in published maps and institutional affiliations. 